\title{
La llegada de Ánforas Hispanas a Germania durante los últimos siglos de la dominación romana. Una cuestión para el futuro.
}

\author{
Horacio González Cesteros. \\ Departamento de Prehistoria y Arqueología de la UAM.
}

\section{Resumen}

Este artículo supone un intento para empezar a sentar bases, donde se apoyen futuras investigaciones referentes al estudio de las relaciones interprovinciales entre el área Hispana y las provincias del noroeste del Imperio romano, a lo largo del mal conocido periodo de la Antigüedad tardía. El objeto principal de estudio son aquellas ánforas, que fabricadas en la Península Ibérica llegaron a las provincias fronterizas de Germania. Partiendo de un análisis de la situación existente y de los contextos arqueológicos más significativos, se pretende calibrar el alcance de la demanda de estos contenedores cerámicos y valorar su aportación al conocimiento de las relaciones comerciales y culturales entre estas dos áreas distantes, así como plantear cuestiones referentes al carácter de los consumidores de las mercancías que en ellos iban envasados.

PALABRAS CLAVE: Ánforas, Germania, Hispania, Salazón, Vino, Aceite de oliva.

\section{Summary}

This paper attempts at setting the groundwork for new studies on the relations between the Hispanic and the Northwestern provinces of the Roman Empire in Late Antiquity. The main subject are the Spanish amphorae that reached the German border territories. An analysis of both, the historical background and of the main archeological contexts, allows us to estimate real significance of the demand and to appreciate the value of these items to understand the commercial and cultural relations between these remote areas. This is also an opportunity to answer several questions about the consumption in North Europe of the Mediterranean products transported in the amphorae.

Desde principios del siglo XX, los historiadores han venido prestando atención al desarrollo histórico del área del Rin en el periodo cronológico que transcurre entre el asesinato de Severo Alejandro en Maguncia en el año 235 d.C., hasta el momento en que Roma dejó de ejercer su control sobre lo que propiamente fueron las provincias germanas del Imperio romano. El interés que suscita el estudio de este área geográfica durante el Bajo Imperio, deriva directamente de la impor- tancia que tuvo la zona, tanto por su carácter de punto fronterizo constantemente amenazado por las cada vez más numerosas confederaciones de pueblos germánicos que se concentraban al otro lado de la frontera (en este caso al otro lado del Rin), como por el esplendor que alcanzaron algunos de sus núcleos más importantes, destacando las capitales de las dos provincias, Colonia y Maguncia, junto con Trier, capital no sólo de la Galia Bélgica, sino de toda la praefectura de las 
Galias a partir de época de Constantino, así como residencia de la corte del César de Occidente desde tiempos de la primera tetrarquía.

Sin embargo, existe un aspecto al que la historiografía moderna no ha prestado la atención adecuada. Me estoy refiriendo al desarrollo de la economía en general y a la cuestión concerniente a las relaciones comerciales con otras áreas en particular. Se trata en mi opinión de una cuestión fundamental, pues es clave para poder entender el desarrollo histórico de las provincias noroccidentales del mundo romano en la Antigüedad tardía, ya que no hay que olvidar que estamos frente a unas regiones que habían sido netamente importadoras de productos mediterráneos durante el periodo Alto imperial.

El triángulo geográfico delimitado por Colonia, Trier y Maguncia, se convirtió en una de las áreas más destacadas de todo el Occidente romano. El influjo de Trier debió provocar la activación económica de toda la zona circundante, centrada en abastecer las principales demandas de la corte y la administración imperial. Así, es bien sabido que desde el siglo II la zona del Mosela y la región alrededor de su desembocadura en el Rin, empezaron a aumentar la producción de vinos, que eclosionaría en los siglos III y IV ${ }^{1}$. A pesar de ello, debido a su propia lejanía con respecto a la cuenca mediterránea y a las características climáticas de Europa central y noroccidental, las provincias norteñas nunca pudieron satisfacer por sí mismas todas las demandas inherentes a la mentalidad y al tipo de vida romanos. Mucho menos pudieron suplir las necesidades de productos de origen mediterráneo demandadas tanto por la corte y administración imperial en ciudades como Trier, Colonia o Maguncia, como por el gran número de soldados romanos asentados en la frontera. Ambos grupos fueron los principales garantes de los valores y costumbres romanas en el área del Rin, por lo menos durante todo el siglo III y IV².

1 Hoy en día se cuenta tanto con pruebas arqueológicas como literarias que nos remiten al auge de las producciones de este área desde fines del siglo III d.C. De tipo arqueológico, destaca la práctica desaparición de la importación de ánforas occidentales a partir de la mitad del siglo III, que afecta especialmente a las importaciones de vinos galos de calidad media o baja, que habían llegado en grandes cantidades durante todo el siglo II, envasados en ánforas de la forma Gauloise 4. En lo que a las fuentes literarias se refiere, bajo el reinado del emperador Valentiniano, Ausonio escribió su
A pesar de la importancia de centros civiles como Trier o Colonia, hay que tener en cuenta que en estos momentos se asiste a un incremento notable de la presión de los pueblos del otro lado de la línea fronteriza, que desde la segunda mitad del siglo III vuelve a estar situada en el Rin. Ello obligó a efectuar importantes remodelaciones militares, construyéndose un gran número de fuertes que siguieron las nuevas concepciones bélicas del momento y que tuvieron puestos de abastecimiento situados en la retaguardia. La existencia de una Annona militaris desde la época de los tetrarcas está fuera de toda duda, al igual que las nuevas bases sobre las que ésta debió de asentarse, donde primaba el avituallamiento a través de las poblaciones más cercanas (Fritz, 2001; Herz, 1988). No obstante, lo normal sería que ciertos productos que habían sido básicos en la dieta de los militares a lo largo del Alto Imperio, continuasen siéndolo en este periodo y por lo tanto llegasen en buenas cantidades. Se trata del aceite de oliva y en menor medida de las salazones, cuyos envases aparecen de manera muy esporádica en los campamentos militares del Bajo Imperio en Germania.

Si bien es cierto que la eclosión de la viticultura en la zona media del Rin y sobre todo en la cuenca del Mosela (Brun, 2005) a partir de finales del siglo II o inicios del III, permitió cubrir una gran parte de la demanda de vino en las regiones germanas, otros productos de origen mediterráneo como salazones y aceite de oliva tuvieron que ser importados, de la misma manera que se venía haciendo a lo largo de los últimos tres siglos. Este hecho lleva a plantearse la posible existencia de una importación masiva de recipientes en los que dichos bienes serían transportados. Sin embargo, en el registro arqueológico del periodo entre la mitad del siglo III y el siglo V, encontramos un panorama bien distinto, ya que hasta el momento en la mayor parte de los centros civiles y militares, tanto ánforas como otro tipo de envases aparecen de forma reducida y siempre en un número muy inferior al de momentos anteriores.

famosa oda al Mosela, en la cual se enaltece a toda la zona en torno a Trier, a los cultivos en las terrazas de dicho río y la enorme productividad de los mismos, destacando el alto número de viñedos de gran calidad. Ausonio, Mosela., 150168.

2 La cuestión de la etnicidad del ejército romano del Bajo Imperio sigue siendo objeto de controversia. Sobre ella volveré posteriormente, pues es uno de los puntos básicos sobre los que se asientan parte de las ideas de este artículo. 
Para explicar el descenso de la presencia de ánforas en los niveles tardoantiguos de Germania se han esgrimido diversas razones. Tradicionalmente se ha argumentado que el declive del comercio privado incidiría muy negativamente, si bien se ha de pensar que en estos momentos el mercado germano está dominado aún más por la alta concentración de consumidores "annonarios" o cuanto menos privilegiados, ya que al ejército hay que sumarle la presencia de la corte imperial en la cercana Trier. Tradicionalmente, para explicar la falta de importaciones anfóricas en estas regiones, se ha recurrido a buscar razones en el origen de los contingentes de los asentamientos militares instalados en las provincias de la Diócesis de las Galias. Desde fines del siglo XIX, la historiografía europea y más en concreto la alemana, ha proyectado la imagen de que en el ejército romano del Bajo Imperio se asiste a una creciente "barbarización", lo que supondría la presencia de gentes cuyas costumbres alimenticias no incluían el consumo de productos marinos, mientras que el aceite de oliva era sustituido por grasas animales. Como se verá posteriormente, la cuestión de la etnicidad de las tropas romanas del siglo IV y $\mathrm{V}$ aún sigue generando mucho debate.

Otra razón que se podría añadir para entender el descenso del número de ánforas importadas, son las mejoras tecnológicas que parecen producirse en los alfares desde finales del siglo II d.C., que posibilitarían la fabricación de envases con igual o mayor capacidad pero con un peso mucho menor, lo que implicaría la posibilidad de enviar una cantidad similar de mercancías, utilizando un número bastante menor de envases ${ }^{3}$. Si bien, por sí sólo este planteamiento se muestra insuficiente para explicar el enorme desequilibrio existente entre la visión con la que actualmente se cuenta para los primeros siglos de presencia romana y la que se tiene a partir del segundo tercio del siglo III d.C.

Estas hipótesis pueden ser planteadas para argumentar parcialmente el evidente descenso de las importaciones anfóricas en las regiones renanas desde inicios del siglo III, pero creo firmemente que la causa principal de que se cuente con menos material anfórico que en épocas anteriores,

3 En el cuadro de Peackok \& Williams, puede verse cómo en los recipientes africanos del siglo III y IV, la relación entre aún se nos sigue escapando y por lo tanto lo más probable es que haya que buscarla en deficiencias de la investigación. Por este motivo, sería de gran importancia efectuar un estudio concienzudo sobre la existencia de ánforas en los dos últimos siglos de presencia romana, pues como bien puso de manifiesto S.Martin-Kilcher hace ya quince años, al Norte de los Alpes siguen faltando publicaciones desde la mitad del siglo III (MartinKilcher, 1994a). Con ello se podría calibrar el alcance de la disminución de importaciones, así como empezar a indagar en las causas de la misma.

\section{EJEMPLOS DE ÁNFORAS TARDOANTIGUAS EN CONTEXTOS RENANOS.}

Una vez planteada la problemática general de las regiones noroccidentales del Imperio romano y de las provincias germanas en particular, es conveniente pasar a analizar algunos de los centros en los que se cuenta con material anfórico encuadrable en este periodo. Empezando por los núcleos poblacionales más importantes es como podrá llegarse a establecer un primer punto de apoyo para avanzar en la comprensión de las relaciones mantenidas entre las regiones mediterráneas y las de Europa central y noroccidental. Para este trabajo se han elegido las ciudades de Colonia, Maguncia y Augst, pues no sólo son los tres asentamientos donde hay mayor número de material encuadrable en el periodo aquí analizado, sino que creo que se trata de tres lugares muy interesantes desde el punto de vista poblacional, al ser los núcleos urbanos más importantes de las provincias de Germania Secunda, Germania Prima y del área suiza de Sequania.

En principio son tres núcleos en los que residiría una gran parte de la jerarquía política, eclesiástica y militar de las respectivas provincias y, por lo tanto deberían de ser lugares especialmente privilegiados a la hora de tener acceso a bienes de importación mediterráneos. El carácter mixto de la población de los tres, puede mostrarse como un inconveniente a la hora de intentar percibir diferencias entre el consumo militar y civil y poder llegar a establecer hipótesis sobre la etnicidad y costumbres de ambos grupos. No obstante,

capacidad y peso del ánfora es bastante mejor que en los envases altoimperiales. (Peacock y Williams, 1988). 
no hay que olvidar que debido a su posición fronteriza, la vida en las provincias germanas del Imperio siempre estuvo marcada por la impronta del ejército.

\section{-COLONIA.}

En los últimos siglos del dominio romano sobre el Rin, la Colonia Claudia Ara Agrippinensium mantuvo su papel como una de las urbes más notables del área renana. Transformada en capital del imperio de las Galias con Póstumo (si bien ya con Tétrico tomaría Trier el relevo), durante todo el siglo IV fue el principal centro político y económico de la provincia Germania II, desde donde se administraban todas las tropas y recursos de la misma.

La existencia de una rica oligarquía urbana ligada a la administración y los negocios, se encuentra fuera de toda duda gracias al gran número de testimonios arquitectónicos $\mathrm{y}$, en menor medida, epigráficos. De igual modo cabría pensar en la alta incidencia de dos instituciones básicas del periodo bajo imperial, el ejército y la iglesia. Nuevos efectivos militares se asientan en Colonia desde el gobierno de Constantino, en cuyo reinado se construyó un nuevo puente sobre el Rin protegido por el castellum de Divitia, con capacidad para albergar a una legión bajoimperial y situado al otro lado del río en el actual barrio de Deutz. Por su parte, la iglesia va ganando cada vez más relevancia conforme avanza el siglo IV, ya que parece observarse un incremento del uso de la simbología cristiana, que va de la mano de un aumento de iglesias y basílicas. ${ }^{4}$

La presencia de depósitos anfóricos relevantes, o por lo menos de aquellos que hayan sido publicados, es bastante escasa, algo que no debe-

4 Entre las construidas en el siglo IV en Colonia, destaca la iglesia de San Severin y la de San Pantaleón, ambas en el extrarradio de la ciudad tardoantigua.

5 La problemática arqueológica de una ciudad como Colonia parece ser el resultado no sólo de una mala gestión, sino también fruto de los problemas urbanísticos derivados de la destrucción de más de un $90 \%$ de su superficie durante los bombardeos aliados de la Segunda Guerra Mundial. En este sentido, el profesor José Remesal me comentó que durante una de sus primeras estancias en la ciudad, arqueólogos locales le habían informado de que una vez finalizada la guerra, con el inicio de la reconstrucción de la ciudad, se tomaron medidas como entregar parte de los vestigios medievales y romanos que los bombardeos habían sacado a la luz, a aquellos ría extrañarnos pues el panorama para época alto imperial no es mucho mejor ${ }^{5}$. Sin embargo, contamos indirectamente con uno de los más destacados contextos anfóricos de la Antigüedad tardía en el área del Rin, que se encuentra en el conjunto arqueológico del mausoleo de Sankt Gereon. Esta monumental tumba se presenta como un edificio de planta oval rodeado de varios ábsides en forma de herradura (hoy en día pueden observarse ocho, si bien no se descarta que en la planta original existiese alguno más), que acababan formando semicúpulas. Su construcción se data generalmente en torno a la década de los 50-60 del siglo IV, probablemente justo después de que la ciudad fuera recuperada por Juliano tras haberla destruido los francos en el 355.

En el mausoleo debió de enterrarse una persona destacable de la ciudad, tal vez un miembro del ejército, un oligarca local, o incluso un alto funcionario perteneciente a la administración imperial $^{6}$. Fue transformado en iglesia martirial ya en el siglo V, pasando a ser una de las más importantes de la ciudad y presentando varias fases constructivas hasta el siglo XIX. Durante la última reforma de mediados del siglo XIX, que afectó relativamente a parte de las bóvedas, pudo observarse el uso de ánforas en el interior de las mismas, aunque sería después de los bombardeos aliados de la Segunda Guerra Mundial, cuando, tras la destrucción parcial de la iglesia, salieron a la luz el interior de muchos de sus muros, entre ellos los de las semicúpulas de los ábsides, que mostraron claramente la utilización de ánforas y mortero para su construcción.

El uso de ánforas para la construcción de bóvedas se documenta en varios edificios (la mayor parte de ellos de carácter sepulcral), en Roma y sus alrededores durante el siglo IV e ini-

particulares que ayudasen en las tareas de recogida y registro de los mismos. Medidas de este tipo, motivadas por la urgencia del momento, a posteriori han demostrado ser catastróficas para tener una visión coherente del panorama arqueológico de Colonia.

6 Las tres propuestas serían factibles, así como el que fuera un oligarca local que a su vez ejerciese un alto cargo del ejército y/o de la administración imperial. Sin embargo, al no tenerse ningún epígrafe que mencione a la persona o personas que aquí se enterraron, su condición no puede precisarse, por lo que no puede afirmarse nada más allá de la propia magnitud del mausoleo, que desde luego invita a pensar en un personaje de alto rango. (Verstegen, 2006). 
cios del $\mathrm{V}^{7}$, así como en Oriente principalmente durante el siglo V y VI. El motivo por el cual se recurre a las ánforas como elemento constructivo, parece estar ligado a cuestiones tanto económicas, al suponer un ahorro de material, como de técnica constructiva, ya que el empleo de materiales cerámicos facilita que el mortero de cal fraguie con mayor rapidez y, al mismo tiempo confiere cierta ligereza a la bóveda al aligerar levemente el peso de la misma ${ }^{8}$.

Dentro de los ejemplos con los que se cuenta, destaca el hecho de que entre las ánforas empleadas, en el $99 \%$ de los casos son asociables al tipo Dressel 23. En una visita a la iglesia de Sankt Gereon en Diciembre de 2007, no pude observar directamente los tres ejemplares expuestos de las cuatro ánforas extraídas prácticamente enteras durante las labores de construcción de mediados del siglo XIX. A pesar de ello, las medidas y los dibujos dados por Ute Verstegen, se corresponden con un tipo de ánfora de la familia de las Dressel 23. Las medidas -entre $68-74 \mathrm{~cm}$ de altura y entre 45,5-48 de anchura exterior-, invitan a pensar en una variante grande de las Dressel 23, que parece cercana tipológicamente a las Keay XIIIc, pero cuyo módulo es mayor y bien podría asimilarse al de la tipología número XV de Keay (Keay, S. J, 1986) ${ }^{9}$. Aún así, es posible que en esta construcción se hubiesen utilizado otros tipos de ánforas, pues una noticia del siglo XIX, menciona ánforas de entre $40-50 \mathrm{~cm}$. de altura, situadas en el inicio de las semicúpulas (Verstegen, 2006: 137) ${ }^{10}$. A tenor de la brevedad de la descripción, no puede confirmarse si estas ánforas de menor tamaño son versiones más pequeñas de Dressel 23, cuya altura canónica suele situarse entre los 50 y $55 \mathrm{~cm}$, o por el contrario se trata de otro tipo desligado de

7 Recientemente, Lancaster ha publicado un excelente trabajo con respecto al uso de ánforas en la arquitectura, poniendo especial atención a los siglos IV y V (Lancaster, 2005).

8 En el libro de Lancaster, se dedica un capítulo entero al uso de ánforas como material constructivo, proponiéndose varias cuestiones para explicar el mismo aplicado a bóvedas. Según cálculos suyos, cree que la reducción del peso de las bóvedas mediante el empleo de ánforas realmente es mínima $(1,43 \%$ en el circo de Majencio, $1,33 \%$ en el mausoleo de Helena), por lo que tiende a darle poca importancia a este factor, en pro de su uso como elemento cerámico que ayuda a fraguar con mayor rapidez. Para ello se basa en que las ánforas aparecen generalmente en lugares especialmente delicados, donde es importante que el muro interior quede bien y rápidamente compactado, como puede ser cerca de los vanos (Minerva Medica, Sankt Gereon) o en la construcción de un pronaos suspendido sobre dos bóvedas corridas, como en el Mausoleo de Tor de'Schiavi en Roma. las ánforas olearias sudhispanas.

El número total de Dressel 23 utilizadas, debió ser elevado, ya que se han documentado en todas aquellas cúpulas cuyo interior quedó al descubierto y la separación entre los diferentes fragmentos es bastante escasa, rondando los $25 \mathrm{~cm}$ (Verstegen, 2006: 137). Según cálculos del Dr. José Remesal, aconsejado por el Dr J. G. Dekers, en la construcción de Sankt Gereon se emplearían más de 1200 Dressel 23, aunque la propia Verstegen sugiere una cifra entre 125 y 400 (Remesal Rodríguez, 1997: 24; Verstegen, 2006: $475)^{11}$. Sin entrar en la problemática del número total de ánforas utilizado, pues es bastante difícil realizar una aproximación exacta, el hecho más importante que la iglesia de Sankt Gereon aporta al tema de este artículo, reside en confirmar que durante la primera mitad del siglo IV continuaron llegando una gran cantidad de ánforas desde las regiones olivareras del sur de Hispania. Su número fue por lo menos el suficiente, como para que una vez vaciadas de su contenido original, pudieran ser utilizadas como material de construcción. Con ello, puede afirmarse sin temor a estar exagerando, que el mausoleo primigenio supone la confirmación de la vitalidad de las exportaciones olearias béticas a la zona media de Germania a lo largo del siglo IV.

\section{-MAGUNCIA.}

Las transformaciones del periodo también se perciben en Maguncia, donde se observan cambios en la fisonomía de la ciudad, que se perciben principalmente en el siglo III mediante la cons-

9 Comparar con el cuadro tipológico desarrollado por P.Berni (1998; 24).

${ }^{10}$ De todas maneras, interpretando la noticia del momento en el que el interior de las semicúpulas quedó al descubierto y teniendo en cuenta que las tres ánforas prácticamente completas con las que se cuenta son del mismo tipo, lo normal sería pensar que la cantidad de ánforas de pequeño tamaño, debió ser muy inferior a la del resto.

${ }^{11}$ En la publicación de la tesis doctoral de Otmar Schwab se aportan unas fotografías en las que puede confirmarse el amplio número de envases cerámicos usados en la construcción de las semicúpulas, que se encuentran formando parte del relleno desde las partes más bajas hasta la zona alta en la que en el siglo XII fueron cortadas para la construcción de las tribunas góticas (Schwab, 2002: 40). 
trucción de un muro perimetral para encuadrar el asentamiento civil. Igualmente a mediados del siglo IV, probablemente coincidiendo con las invasiones de 352, el perímetro amurallado se restringe y queda prácticamente ajustado a lo que es la muralla de la Legio XXII Pía fidelis, la legión asentada en el campamento tardoimperial. No obstante, como capital de la provincia Germania II, Maguncia sigue siendo un núcleo importante y disfruta del auge de Trier y la zona del Mosela, lo que haría que llegasen un buen número de ánforas, en principio superior al de la mayor parte de centros urbanos de Germania, a excepción de Colonia.

En el estudio realizado por U. Ehmig (2003), vemos que hay muy poca representación anfórica a partir de mediados del siglo III. Aún así, se observan una serie de tipologías que ponen de manifiesto la presencia de productos de origen africano, oriental e hispano. En este caso, las producciones hispanas están representadas por debajo de las africanas y orientales. Esta situación se debe al poco peso de las ánforas olearias sudhispanas desde el siglo IV, ya que si bien para la segunda mitad del siglo III, puede que nos encontremos aún con algunas Dressel 20 tardías trayendo aceite a Maguncia, hay que destacar que únicamente está constatada la presencia testimonial de Dressel $23^{12}$. Por otra parte, hay documentadas nueve piezas pertenecientes a la forma Almagro 51C-Keay XXIII, sin especificarse una producción bética o lusitana de la misma y un fragmento que coincidiría con el tipo Matagallares $\mathrm{I}^{13}$, pro-

\footnotetext{
${ }^{12}$ En los perfiles de los labios aparecen varios ejemplares pertenecientes al grupo H de Martin-Kilcher (1987), que es en el que quedarían encuadradas las últimas Dressel 20 y las Dressel 23. A mi entender la ausencia de ánforas de aceite béticas tardoantiguas en Maguncia se debe a la falta de material en los pocos contextos arqueológicos de estos momentos, que han sido excavados hasta la fecha.

${ }^{13}$ Esta tipología anfórica fue definida a raiz de la excavación del alfar granadino de Los Matagallares (Bernal Casasola, 1998).

${ }^{14}$ Es cierto que la producción y comercialización de ánforas en las provincias andaluzas de Granada y Málaga es peor conocida que la de Cádiz o el Valle del Guadalquivir. A pesar de que el volumen de producción nunca alcanzaría el de las zonas anteriormente nombradas, los hallazgos arqueológicos de las últimas décadas cada vez ponen más en relieve la relativa importancia que la zona costera mediterránea de la Bética tuvo en la exportación de productos capaces de ser envasados en ánforas, especialmente en el periodo tardoan-
}

bablemente proveniente del área costera granadina o malacitana ${ }^{14}$. La presencia de ánforas salazoneras tal vez nos esté hablando de cómo, tras la práctica desaparición de las exportaciones en la segunda mitad del siglo III, las factorías hispanas parecen volver a enviar sus productos al área del Rin.

Estas importaciones, demuestran la presencia de productos mediterráneos en Mainz durante el Bajo imperio, aunque, a falta de nuevos datos, puede decirse que en un número bastante reducido en comparación con el periodo Altoimperial ${ }^{15}$ y que esperemos pueda ser ampliado por medio de nuevas intervenciones arqueológicas y del avance de la investigación.

\section{-AUGST.}

La dinámica general del siglo III en Germania, afectó a este importante asentamiento del Noroeste de Suiza, que parece vivir un declive progresivo en el volumen de importación de las mercancías envasadas en ánforas. A lo largo del segundo y tercer cuarto del siglo III, la colonia sufrió una pérdida constante de población, muy acentuada en la década de los setenta, cuando la ciudad fue destruida por los alamanes en su avance hacia el Norte de Italia. Este hecho propició el final de la aglomeración urbana conocida como Colonia Augusta Rauracorum.

Sin embargo, el solar de Augst no fue abandonado en su totalidad, o al menos sólo lo estuvo temporalmente, ya que pocos años después, pro-

tiguo. Para los talleres de cerámica de la actual provincia de Granada un buen estudio de conjunto se encuentra en Fernández García (2004; 239-272). En cuanto a los estudios relativos a la producción anfórica en la provincia de Málaga destaca la obra colectiva (Figlinae Malacitanae. La producción de cerámica romana en los territorios malacitanos. Málaga), así como el trabajo de Serrano Ramos incluido en el congreso sobre producciones cerámicas béticas (Figlinae Beaticae: Talleres alfareros y producciones cerámicas en la Bética romana (ss.II a.C.-VII d.C.): actas del Congreso Internacional, Cádiz, 12-14 de noviembre 2003. 2004; 161194).

${ }^{15}$ Ulrike Ehmig señala que las ánforas encuadrables en los últimos siglos de ocupación romana, tanto en Augst como en Mainz suponen cerca del 2\% del total de ánforas encontradas en ambos lugares (Ehmig, 2003; 41). 
bablemente bajo el reinado de Diocleciano, nos encontramos con que en la parte más septentrional de la antigua colonia se alza un Castellum de 3,7 ha, el denominado Castrum Rauracense ${ }^{16}$. Desde los años centrales del siglo III se observa el aumento de la presencia militar en Augst, materializada en los restos de cultura material, por lo que puede pensarse que quizás estuviese presente algún destacamento con anterioridad a la creación del Castellum, cuyo nombre nos es desconocido. En lo referente a la fortaleza de tiempos de Diocleciano si que conocemos el nombre de la legión en ella asentada, se trata de la Legio I Martia, o cuanto menos algún destacamento suyo como puede deducirse a tenor de las pruebas epigráficas. La función de estas tropas sería asegurar la protección de la frontera y servir de cabecera para una posible penetración más allá del Rin, como parece indicar la existencia de un fuerte de reducidas extensiones justo al otro lado del puente sobre el Rin.

No obstante, la zona no debió de tener únicamente una ocupación militar, sino que se constata la presencia de civiles por lo menos hasta los años centrales del siglo IV, cuando la fortaleza debió de ceder ante el empuje de Francos y Alamanes. A pesar de los destrozos ocasionados por los ataques germanos, la continuidad de la presencia romana nada está asegurada hasta el primer decenio del siglo V. Esta serie de cambios históricos son fundamentales para acercarnos a la evolución de las importaciones anfóricas en los últimos tiempos de la presencia romana, si bien es cierto que nuestro conocimiento aún es limitado, ya que el volumen del material es bastante menor del que cabría esperar.

El descenso general de las importaciones se debió probablemente a las dificultades con las que se encuentra el comercio interprovincial en el siglo III o en ciertos momentos del IV y V, pero también al aumento de la producción local de ciertos bienes, como el vino de las provincias germanas y del norte de la Galia. En Augst, el descenso es muy notable si se compara con los niveles de etapas anteriores, pero aún continuaron llegando ánforas, incluso hasta mediados del siglo V d.C.

\footnotetext{
16 Ammiano Marcelino parece referirse al mismo como Rauracos, si bien el nombre que actualmente se utiliza es el de Castrum Rauracense. Amm Mar. XVI, II, 1-6.
}

Un hecho a tener en cuenta es que mientras en los dos cuartos centrales del siglo III las importaciones vinarias galas alcanzan su mayor apogeo porcentualmente hablando, desaparecen totalmente a partir del fin de la colonia y la creación de la fortaleza militar, sin encontrarse un único ejemplar a lo largo de todo el siglo IV. Por otra parte, desde época de los severos se viene observando un aumento paulatino de las ánforas venidas de las provincias del Norte de África, con la presencia de envases fabricados en Mauritania Caesarensis, Africa Proconsular o la Bizacena ${ }^{17}$.

Ante estas transformaciones resulta primordial ver la manera en la que reaccionaron las importaciones hispánicas, pues si bien es cierto que la cantidad total de productos disminuyó notablemente, sobre todo a partir de la destrucción de la colonia, los envases peninsulares siguieron teniendo una gran relevancia porcentual dentro del conjunto anfórico. Para ello, conviene analizar el material en función de la división cronológica que supone el fin de la ocupación de la colonia y el inicio del castellum.

Desde el final de la dinastía de los Severos, hasta la creación del Castrum Rauracense parece que se está ante una etapa transitoria en la que se definieron las pautas que dominaron durante todo el siglo IV. Una de ellas es que desde la Península Ibérica únicamente se observa la llegada a Augst de envases asociados con las salazones y el aceite de oliva, dejando de estar presentes de manera definitiva ánforas asociadas a vino y de otros productos tales como las aceitunas o el defrutum, que ya llegaban con muy poca frecuencia en el siglo II d.C. Al igual que en época antoniniana, el aceite continuó siendo el producto mejor representado, pero existen bastantes diferencias en cuanto a la cantidad de envases olearios béticos que llegan, así como su incidencia sobre el total de ánforas de Augst. Este se sitúa en un porcentaje algo superior al 30\%, siendo más del $85 \%$ entre los envases hispanos. Sin embargo, en relación con el descenso cuantitativo del material anfórico, en el caso de la importación de ánforas olearias sudhispanas se percibe un bajón muy importante desde la muerte de Severo Alejandro hasta el periodo final de la

${ }^{17}$ Las ánforas tardoantiguas africanas aparecen clasificadas en los grupos 5 y 18 de Martin-Kilcher (1994b, Volumen II; 444-450). 
colonia, que probablemente haya que poner en relación con varios factores.

El primero de ellos, común al conjunto del material anfórico, tendría que ver con las dificultades con las que puede hallarse el comercio interprovincial en estos momentos, especialmente el comercio no ligado al abastecimiento del ejército. Es cierto que los problemas políticos y económicos del siglo III llevarían a una contracción del intercambio entre las diferentes áreas del mundo romano, pero aún está por demostrar la relevancia del mismo. Un factor más importante parece ser la pérdida de población de la colonia, bastante acusada desde el segundo tercio del siglo, y la más que probable pérdida de riqueza de la población restante. Por último, hay que mirar con atención al lugar de producción del aceite importado en Augst. La Bética continúa siendo el principal proveedor de Augst, pero como ya se ha mencionado, las ánforas africanas comienzan a estar más representadas, adquiriendo cierta importancia porcentual y configurándose como una nueva fuente de abastecimiento que con anterioridad apenas tenía relevancia. No obstante, el número de africanas enmarcables dentro de este periodo está muy por debajo del de las béticas y muchas de ellas no debieron de contener aceite, sino salazones o incluso vino ${ }^{18}$. Por otra parte, hay que destacar que con la llegada de Septimio Severo al trono de Roma y como consecuencia de las nuevas relaciones de poder dentro del Imperio, en la Bética se debió de llevar a cabo una reestructura-

18 Desde hace un tiempo viene superándose la visión tradicional que ligaba a casi cualquier tipo de ánfora producida en el norte de África con el aceite de oliva. En Augst las ánforas africanas mejor representadas son aquellas encuadrables dentro de la familia de las Keay 25 del siglo IV, de las que desde hace tiempo viene dudándose su contenido, ya que hay numerosos ejemplos que aparecen con las paredes con una capa de brea, lo que eliminaría al aceite de consumo alimenticio como supuesto contenido. En Augst se tienen dos ejemplos de paredes con restos de brea sobre supuestas ánforas Keay 25, si bien Martin-Kilcher (1994b, Volumen II; 449) menciona que una de ellas bien puede tratarse de una Africana II del siglo III, predecesora de las Keay 25. La obra más completa y reciente que aborda el tema del contenido de las ánforas africanas es: BONIFAY, M. (2004).

${ }^{19}$ Las consecuencias que las requisiciones de Septimio Severo tuvieron sobre la producción de aceite bético, fueron ya observadas por los investigadores españoles del Monte Testaccio (Rodríguez Almeida 1980. y Remesal Rodríguez 1983). Un interesante trabajo puede verse en: LO CASCIO, E (2003). ción de los engranajes de producción agrícola que afectarían seriamente al Valle del Guadalquivir, por medio de requisiciones y de un mayor control estatal sobre la producción olivarera ${ }^{19}$.

Estos cambios tienen su reflejo en los envases encargados del transporte del aceite, observándose a finales del siglo III o inicios del IV, cómo las Dressel 20 empiezan a ser sustituidas por formas más pequeñas, que en Augst se encuentran representadas por las Dressel 23 y las Tejarillo 1. La epigrafía anfórica también nos habla directa e indirectamente de las transformaciones que sufre el sistema productivo del campo bético, y en Augst, entre finales del siglo III e inicios del IV, únicamente se tiene tres sellos provenientes de la zona de Arva y El Tejarillo, uno de ellos es el ampliamente difundido de $\mathrm{PNN}^{20}$.

En cuanto a las salazones, las hispanas parecen ser las más comunes en Augst en el periodo anterior a la creación del castellum. Sin embargo, no llegan a suponer más del $6 \%$ del conjunto de ánforas de estos momentos y c.a $15 \%$ entre las hispanas. La mayor parte de ellas provienen de la Bética pero también parece que se cuenta con algún ejemplo de importaciones lusitanas ${ }^{21}$. En cuanto a los envases se observa la pervivencia de las formas Beltrán IIB/Augst 30 y de alguna Dressel 14, hasta los últimos momentos de la colonia. El descenso en la llegada de envases anfóreos de salazones y salsas de pescado en toda Europa noroccidental, parece ser un proceso con-

${ }^{20}$ Se ha tendido a asociar este sello y, ligado a él PNNF, con la forma Dressel 23, si bien en el Testaccio aparecen ampliamente sobre Dressel 20 del siglo III. Tal vez, en el caso de Augst, como en el de otros contextos del área renana tales como Grand y Saint Ulrich (Lorena) Xanten, o Estrasburgo (Baudoux, 1996; 87), se trate de formas pequeñas de Dressel 20, es decir, de las denominadas parvae, de las que derivarían las Dressel 23. (Berni Millet, 1998). Ambos sellos son bastante comunes en la epigrafía de finales del siglo II y del siglo III, como puede verse en la base de datos del CEIPAC.

${ }^{21}$ En el trabajo de S. Martin-Kilcher, el único defecto de importancia que encuentro es que no parece distinguirse entre algunas producciones béticas y las lusitanas. Exculpando a la autora, hay que decir que la situación actual de conocimiento con la que se tiene hoy en día en Portugal no es ni por asomo aquella con la que se contaba en el momento en el que el trabajo sobre el material de Augst fue redactado. No obstante, en el área renana tal vez haya que prestar más atención a las importaciones de la costa portuguesa, en especial a aquellas de los estuarios del Tajo y Sado, donde el volumen de producción de algunas factorías de salazones fue enorme. 
tinuo desde finales del siglo I. Las causas del mismo no están muy claras, aunque desde mi punto de vista bien pueda deberse a cambios en las costumbres alimenticias -pues no hay que olvidar que las salazones aparecen como uno de los ingredientes más importantes de la cocina romana $^{22}$, o a que en estas regiones, una vez se ha asentado la cultura y administración romana, empieza a contarse con otro tipo de aportes de $\mathrm{sal}^{23}$.

En el periodo que transcurre desde la creación del asentamiento militar hasta los inicios del siglo $\mathrm{V}$, se observa definitivamente el cambio a las tipologías propias de la Antigüedad tardía. Así, el aceite bético alcanzó Augst envasado en Dressel 23 y en algunas Tejarillo 1, mientras que las salazones lo hicieron exclusivamente en Almagro $51 \mathrm{C}^{24}$.

Las importaciones hispanas ampliaron su incidencia porcentual, si bien el volumen de estos momentos es muy inferior al de épocas anteriores. Suponen alrededor del 52\% del total, destacando la llegada de ánforas de aceite bético, que se acercan al 47\% del conjunto anfórico, con un porcentaje por encima del $90 \%$ en el total de las procedentes de la Península Ibérica. Las salazones, se mantienen al nivel porcentual de mediados del siglo III, con valores algo inferiores al 5\% y $10 \%$ respectivamente, si bien puede afirmarse que su presencia a lo largo del siglo IV, aún siendo poco más que testimonial, parece incrementase con respecto a los dos cuartos centrales del siglo III.

Puede afirmarse que una vez superado el dramático descenso de las importaciones de productos envasados en ánforas en el periodo que abarca desde la muerte de Severo Alejandro hasta el gobierno de los tetrarcas, las pautas de importación de ánforas hispanas se mantienen bastante

${ }^{22}$ En el libro de Apicio De re coquinaria, de época del emperador Nerón, aparecen formando parte de un número bastante significativo de recetas.

${ }^{23}$ El gran número de ánforas de salazón aparecidas en yacimientos, preeminentemente militares, de las provincias germánicas desde el periodo de la conquista hasta época flavia indican que probablemente la mayor parte de las salsas y salazones tendrían una calidad mediocre, siendo importadas principalmente por su valor como aporte diario de sal en una región que en esos momentos sería deficitaria. Es posible pensar que en su exportación desde Hispania, el Estado intervendría de una u otra manera para asegurar la salud y bienestar de las tropas. constantes durante todo el siglo IV y si se compara con los productos que llegan de otras áreas, las exportaciones de la Península Ibérica siguen demostrando una alta competitividad dentro del mercado germano.

\section{LA ROMANIDAD TARDÍA EN LAS PROVINCIAS germanas. Problemas de población Y ETNICIDAD EN LA ORILLA IZQUIERDA DEL RIN Y SU RELACIÓN CON EL REGISTRO ANFÓRICO.}

Como acaba de mencionarse, al comparar la situación de este periodo con la de los primeros dos siglos y medio de la presencia romana en el área renana, la importación de ánforas es mucho menor y por lo tanto, a pesar de la mayor capacidad de los envases del Bajo Imperio, o de la supuesta sustitución de las ánforas por otros envases no cerámicos, cabría pensar que la demanda y el consumo de los productos en ellos envasados se restringe notoriamente. Esta situación ha llevado directamente a mirar hacia posibles transformaciones en la población asentada en las provincias romanas del norte de Europa, si bien generalmente se ha descuidado hacer hincapié en la escasez de datos arqueológicos que se tienen sobre los siglos III, IV y V en la zona ${ }^{25}$.

Aún así, el descenso tan marcado en la llegada de ánforas al área renana, induce directamente a pensar en una reducción del consumo de productos básicos de la dieta mediterránea, principalmente del aceite de oliva y otros derivados del olivo y, en menor medida de las salazones y salsas de pescado. Igualmente, se observa una disminución de la importación de aquellos productos alimenticios mediterráneos ligados a una demanda de mayor poder adquisitivo y por lo tanto de las clases más acomodadas de la sociedad de las

${ }^{24}$ Destaca la ausencia de otras tipologías producidas tanto en la Bética como en Lusitania. Este es el caso de las Almagro 50 o las Beltrán 72, para las que no se ha documentado ni un único ejemplar en Augst.

${ }^{25} \mathrm{El}$ desconocimiento de esta época parece deberse tanto a la dificultad de su estudio por la continuidad de la ocupación hasta día de hoy, como a innegables lagunas y negligencias en las excavaciones. En este sentido, parece que la investigación alemana del siglo XIX e inicios del XX, habría seguido en cierta medida el modelo de Schliemman en sus excavaciones de Troya, intentando llegar a los niveles más iniciales y minusvalorando las fases más recientes de muchas excavaciones. Agredezco al Dr Stefan Altekamp sus interesantes charlas al respecto. 
provincias germanas. Entre estos últimos habría que destacar los grandes vinos mediterráneos, como los producidos en la región del Lazio y Campania, en el Egeo y desde el siglo IV en el área levantina ${ }^{26}$, o ciertos frutos secos, dátiles y otras exquisiteces, que llegan en cantidades muy reducidas o bien directamente no hay constancia de ellos en estos momentos. Este hecho no deja cuanto menos de ser digno de atención, pues con la importancia que adquiere Trier y su área circundante, así como Colonia, cabría esperar cierto incremento del número de consumidores potenciales con alto poder adquisitivo.

La riqueza de ambas urbes y la existencia de un comercio de alto poder adquisitivo durante todo el siglo IV, queda contrastado al observar la llegada de mármoles de gran calidad procedentes de todas las partes del mundo romano. Así, en edificios tanto oficiales -véase el Praetorium, remodelado en la segunda mitad del siglo IVcomo privados -varias villas suburbanas, o el propio Sankt Gereon-, se confirma la presencia de mármoles africanos, itálicos y del área egea entre otros (Verstegen, 2006; 512-513. Eck, 2004; 664-681). La existencia de este comercio de mármoles vuelve a plantear el problema de la falta de estudios en profundidad que aborden la importación de ánforas tardoantiguas en núcleos como Trier o la misma Colonia, donde si bien es cierto que se tiene el conjunto de Sankt Gereon, no hay que olvidar que las ánforas del mausoleo fueron seleccionadas para un uso muy concreto y por lo tanto han de ser entendidas como una muestra significativa de la importancia de la llegada de aceite bético a la capital de la Germania II, sin darnos más pistas sobre el resto de productos $^{27}$.

No obstante, a pesar de la importancia relativa del consumo ligado a las clases altas, tanto en el Alto como en el Bajo Imperio, referirse a las

\footnotetext{
${ }^{26}$ Se cuenta con muy pocos ejemplares de procedencia oriental para estos momentos, y únicamente están documentadas algunas ánforas de Palestina y el área del Egeo y Anatolia en Augst y Mainz. En una reciente ponencia con motivo del congreso de la SFECAG de Colmar 2009, Sandra Amman y Silvia Fünfschilling presentaron los resultados del material cerámico de las excavaciones más recientes llevadas a cabo en el área del Castrum de Augst, con una estatrigrafía de la segunda mitad del siglo IV. En ellas tan sólo parecen haberse encontrado fragmentos de una Keay 1B con probable origen en el este de Mauritania Caesarensis y una LRA 4, cuya tipología se asemeja al tipo B (encuadrable en el siglo V).
}

regiones fronterizas del mundo romano supone hablar de la presencia del ejército y de la alta influencia de los soldados en el devenir cotidiano de estos territorios. En el caso de Germania puede decirse que desde el siglo III fue una de las regiones que más sujeta estuvo a presiones exteriores, siendo constantes las incursiones y saqueos de los pueblos bárbaros del otro lado de la frontera. Sin embargo, ello no debería llevar a engaños y menospreciar la fuerza y capacidad del ejército del Bajo Imperio, como generalmente ha sido el caso, ya que en los momentos en los que una gran parte de sus efectivos no fueron requeridos en otros lugares (hecho que ocurrió con bastante frecuencia), el ejército de Germania pudo por sí mismo mantener la seguridad de las regiones fronterizas, cuanto menos hasta el inicio del siglo $\mathrm{V}$, y probablemente su propia presencia disuadiría a las poblaciones del otro lado del Rin de cara a iniciar una incursión en tierras romanas.

La creencia en la poca capacidad de lucha de las tropas romanas bajoimperiales, no es el único prejuicio con el que nos encontramos a la hora de abordar al ejército romano de este periodo, ya que puede decirse que unido a ello se encuentra la idea de la alta presencia de elementos de origen bárbaro que sirven en estos momentos dentro del ejército imperial. Esta idea, emana directamente de las concepciones de la historiografía alemana de finales del siglo XIX y primeros decenios del siglo XX y por lo tanto conviene que sea observada cuanto menos con cautela. Si bien es cierto que el tema ha generado un gran debate historiográfico desde el final de la Segunda Guerra Mundial, también lo es que la mayoría de los historiadores continúan pensando que los contingentes militares romanos de los siglos IV y V estaban compuestos en un alto número de bárbaros, principalmente de origen germano, llegándose a una "barbarización" del ejército romano durante estos

Esta última ánfora generó un interesante debate que probablemente aparezca en las actas del congreso.

${ }^{27}$ Un estudio en profundidad del material cerámico y del vidrio de Trier, daría datos de inestimable valor para poder comprender la importación de mercancías en el área central de la Germania romana, y poder discernir posibles diferencias entre las distintas capas sociales. En el caso de Colonia, hoy en día se cuenta con algo más de información, pero continúa siendo insuficiente para empezar a buscar respuestas a las preguntas más interesantes relacionadas con comercio, población y consumo. 
siglos ${ }^{28}$. Desde mi punto de vista, esta concepción deriva directamente de una interpretación casi exclusiva de las fuentes escritas referentes al periodo, unido a la utilización de ciertos datos arqueológicos de una manera muchas veces arbitraria ${ }^{29}$.

Si bien es cierto que probablemente el peso de la población de origen bárbaro o cuanto menos semibárbaro, fue creciendo durante el siglo IV y tal vez en las provincias de Germania se notase más que en otros lugares, también lo es que éste no parece ser significativo como pronto hasta el último tercio del siglo ${ }^{30}$. Los vacíos y dificultades de la investigación arqueológica referidos a estos momentos, hacen difícil poder llegar a comprender el verdadero desarrollo de la población asentada en el interior de la provincias de Germania en este interesante periodo cronológico. Probablemente, un estudio más concienzudo de ánforas y otros tipos de cerámicas, podrían ayudar a empezar a resolverlo.

La asociación entre alimento y etnicidad ha sido y es motivo de análisis constante por parte de los antropólogos. La evidencia cerámica es una de las muestras más importantes con la que se cuenta a nivel arqueológico para conocer la dieta y costumbres alimenticias de una sociedad. En el caso de las ánforas y su relación con la población que las consumía en el mundo antiguo, César Carreras en su trabajo sobre las ánforas de aceite en Britannia, hace una excelente exposición a la cual me remitiré a partir de estos momentos (Carreras Montfort, 1998). De este modo, aceptando planteamientos referentes a que los hábitos alimenticios son una de las principales muestras de etnicidad, observamos que durante los primeros siglos del Imperio romano, arriban un buen número de productos de origen mediterráneo a los

\footnotetext{
${ }^{28} \mathrm{El}$ número de historiadores que hablan de la alta presencia de efectivos bárbaros en el ejército romano de los siglos III y IV es interminable, destacando que ésta corriente continúa estando a día de hoy muy extendida entre los estudiosos de la Antigüedad, lo que beneficia el que haya una bonita discusión al respecto y ha de incentivar a los investigadores a ahondar en este tema.

${ }^{29} \mathrm{Al}$ igual que los escritores antiguos, que probablemente dieron tanta importancia a la presencia bárbara dentro del ejército, debido a que les llamaba la atención que hubieran gentes "no romanas" en puestos altos de una institución que había sido y era el garante de los valores y la seguridad de Roma, algunos historiadores y arqueólogos de hoy en día han tendido a sobrerepresentar la incidencia de elementos
}

territorios renanos bajo control de Roma. Estos productos llegan principalmente a ciudades y establecimientos militares, siendo un tanto escueta su presencia en asentamientos civiles secundarios, donde viviría la gran mayoría de la población autóctona.

La muestra tan reducida con la que se cuenta para el periodo bajoimperial, podría llevar a pensar rápidamente que a priori, la falta de ánforas puede estar indicando en dirección a una importancia cuantitativa de un tipo de población en cuya dieta no figura el consumo habitual de productos mediterráneos. Si bien esta premisa es probablemente acertada desde mi punto de vista no tendría por qué significar la existencia de una población cuyo origen se encuentra mayoritariamente al exterior de las fronteras de Roma. En este sentido, de nuevo César Carreras, basándose en Balsdon y en un texto de Dionisio de Halicarnaso dice que las sociedades del norte de Europa, tras el contacto con los romanos incorporaron el vino en sus dietas, mientras que rechazaron el aceite de oliva por su gusto y olor (Carreras Monfort, 1998; 68) ${ }^{31}$.

Esto lleva a plantearnos ciertas cosas. La principal de ellas es que la gran mayoría de la población civil de las provincias galas y germanas, durante todo el periodo romano, habría consumido aceite de oliva en muy escasas ocasiones, como bien parece demostrar el escueto número de ánforas de aceite que se encuentran en los núcleos civiles secundarios y el uso que generalmente se les da a las mismas, siendo utilizados en una gran parte de los casos a la manera de grandes contenedores de almacenamiento ${ }^{32}$. Esto sería debido a que en la dieta cotidiana de la sociedad galorromana o germanorromana, se hacía uso de otro tipo de grasas, como se había hecho en el

clasificables como bárbaros en el registro arqueológico del siglo IV y parte del V d.C.

${ }^{30}$ Ver páginas siguientes.

${ }^{31}$ Sin embargo, la interpretación del texto de Dionisio de Halicarnaso (Ant Rom XII 11.) puede que no sea del todo correcta.

${ }^{32}$ Ejemplos de este uso en las provincias germanas, entre otros, se tienen en el siglo I d.C., en el asentamiento civil De Horden cerca de Utrecht en Holanda (Van der Werff, 1987), o en el siglo II d.C., en el de Wahlheim en el estado de Baden-Württemberg en Alemania (Carreras Monfort, 2004). En un trabajo reciente de J.T Peña (2007), aborda ampliamente el tema del uso secundario de las ánforas. 
periodo anterior a la conquista y como se hizo con posterioridad, pues aún hoy en día su uso no está ni mucho menos generalizado en los países de Europa central y septentrional. En el caso de las salazones parece que tampoco formaron nunca parte de la dieta cotidiana de estas sociedades ${ }^{33}$. Mientras tanto, como ya apuntó Dionisio de Halicarnaso, el consumo de vino sí que estuvo ampliamente difundido entre galos y germanos una vez que entran en contacto con Roma. Pero como se ha mencionado al inicio de este trabajo con la aparición de una producción vinaria a gran escala en la zona del Mosela y el medio Rin, desde finales del siglo II el vino local cubriría cuanto menos, las necesidades de la población civil de menor poder adquisitivo, así como las de las tropas allí estacionadas.

Por otra parte, si bien cabría pensar que la población de la llamada Germania libera no debió consumir nunca grandes cantidades de productos importados de la cuenca mediterránea, su presencia, sobre todo para las clases dirigentes, no les era ajena. En este sentido parece abogar una disposición del Corpus Iuris Civilis en la que se dice que los emperadores Valentiniano, Valente y Gratiano prohibieron la exportación de vino, aceite y liquamen a los territorios bárbaros ${ }^{34}$. En este caso, estamos hablando de los tres productos que con mayor asiduidad utilizaban ánforas para su comercialización, por lo que cabría plantearse que entre los territorios del Imperio y aquellos al otro lado del Rin, se llevaría a cabo un fructífero comercio en el que los preciados líquidos llegarían a varios lugares de población germana envasados en ánforas, o cuanto menos en recipientes cerámicos de mediano tamaño. A día de hoy no se tiene ningún estudio que haya abordado el tema en profundidad, por lo que no pueden resolverse preguntas claves como con qué asiduidad llegaban estos productos al otro lado de la frontera,

\footnotetext{
${ }^{33} \mathrm{Si}$ bien es cierto que con la extensión del cristianismo comienza poco a poco a establecerse un consumo más o menos regular de pescado y empiezan a proliferar los pescados ahumados, tales como la caballa en las zonas costeras y los pescados de río en las áreas interiores.

${ }^{34}$ CJ. IV 41 1. Referente al periodo 370-375. Al referirse al aceite, debe de hacerlo al aceite de oliva, ya que otros como el de risino los podrían producir también al otro lado de la frontera y probablemente no tendrían muchas necesidades de importarlo. Igualmente, el que sean mencionados junto con el vino y sobre todo con el liquamen, posiblemente indique
}

quiénes eran los que los consumían, o de qué forma lo hacían. A pesar de las carencias de la investigación, el texto me parece significativo, pues creo que muestra que una supuesta alta concentración de población de origen germano, no tiene necesariamente que significar un consumo restringido de los productos mediterráneos envasados en ánforas.

Las causas de la falta de ánforas en el registro arqueológico actual de las provincias germanas en los últimos siglos de la presencia romana continúan sin estar resueltas, pero es seguro que hay que buscarlas en una conjunción de varios factores. La cuestión étnica debió de jugar un papel muy importante, pero como ya he mencionado anteriormente, no creo que se tenga que hablar de una barbarización del ejército y sociedad, sino más bien hay que ver que con las reformas que se realizan en el ejército y administración en época de los tetrarcas y de Constantino, se busca una mayor implicación de la población local en la defensa del Imperio.

En esta dirección indica la alta presencia de gentes de la Galia en el ejército romano del siglo $\mathrm{IV}$, siendo lógico pensar que una gran parte de sus efectivos sirvan en aquellos lugares que les son más cercanos, como el norte de Galia y la frontera del Rin.

Esta hipótesis quedaría respaldada si se tienen en cuenta tanto la evidencia filológica como la arqueológica. En el caso filológico hay que reinterpretar de nuevo lo que dicen ciertos autores antiguos acerca del ejército, pues probablemente, si se dejan a un lado los prejuicios acerca de la entrada de gentes extranjeras en el ejército, pueda entreverse mejor la verdadera composición del mismo $^{35}$. Igualmente, desde el punto de vista prosoprográfico, a priori, en la mayor parte del siglo IV no parece observarse la supuesta presencia de

un mismo orígen, o cuanto menos una misma forma de control de los mismos, que tendría que ver con su carácter como mercancías de exportación de cierto valor.

35 Ammianno Marcelino (XX. 8, 15-16), al transcribir una carta que le envía Juliano a Constante II, en respuesta a las peticiones del segundo con respecto al envío de tropas al frente persa, le asegura el envío de caballos hispanos y de auxiliares Laeti, pero le habla de la necesidad de que los galos que parecen formar el grueso de su ejército, se queden en Galia, pues abandonarían a sus familias y dejarían sin protección unas tierras que ya han sufrido bastante. 
grandes contingentes de origen bárbaro, por lo menos en los altos mandos del ejército, que es donde los autores contemporáneos parecen insistir con más énfasis. Así parece ponerlo de manifiesto Hugh Elton en un estudio llevado a cabo hace poco más de una década (Elton, 1996; cap. 5). Si bien es cierto que, como el mismo autor admite, se cuenta con una reducida muestra de nombres para poder entrever la procedencia de los oficiales de rango medio y alto, al igual que para los soldados más bajos, hay que tener en consideración que a día de hoy, habría que descartar el origen de la gran mayoría de ellos, estando bastante presentes las poblaciones del norte de Galia y del área de las provincias germanas, así como ilirios e isaurios (Elton, 1996; Appendix 2).

El campo de la arqueología refuerza la idea de una alta incidencia de las poblaciones locales en el ejército tardorromano de Germania. A pesar de que una vez más, se cuenta con un número limitado de datos, parece que tanto por las estructuras de habitación, como por las tumbas, en el norte de Galia y Germania, todo indica a pensar en una continuidad con los hábitos y costumbres de épocas anteriores. Este panorama continuista, quedaría salpicado ligeramente por la presencia ocasional de elementos exteriores. El mejor ejemplo del que se dispone es el núcleo de Gelduba (Krefeld, en Nordrhein-Westfallen), que cuenta con una enorme necrópolis, así como con estructuras habitacionales datables en este periodo y cuyo panorama arqueológico es del todo asimilable con la lógica evolución de la sociedad de época altoimperial a este lado del $\operatorname{Rin}^{36}$.

Según sabemos por ciertos papiros y relatos de escritores del momento, desde el gobierno de Diocleciano, existió a ciencia cierta una Annona militar que cubriría las necesidades de los soldados. En el caso del ejército de la Diócesis de las Galias, las necesidades de las tropas quedarían satisfechas en su gran mayoría por los mismos territorios donde estaban asentadas, o por los más cercanos, tanto geográfica como administrativamente.

Un panorama distinto parece tenerse en la frontera del Danubio oriental, donde la Annona

\footnotetext{
${ }^{36}$ Para la necrópolis de Gelduba R. Pirling publicó a inicios de los años noventa un buen trabajo referido al tema de la etnicidad de las tumbas (Pirling, 1993). El tema de las estructuras de defensa y habitación de época tardoantigua también ha sido estudiado en el mismo núcleo (Reichmann,1999).
}

militar sí que se vería forzada a importar productos típicos de la dieta mediterránea, especialmente aceite de oliva y vino. En un interesante trabajo que esperemos sea ampliado, Olga Karagiorgou analiza la llegada de ánforas olearias (LRA 2) y vinarias (LRA 1), desde el Egeo y Cilicia-Siria, a las tropas estacionadas en el norte de los Balcanes y la desembocadura del Danubio (Karagiorgou, 2001). A tenor de los datos presentados por Karagiorgou, que abarcan desde el siglo III al VII, parece observarse la continua importación de Late Roman 1 y sobre todo de Late Roman 2, en centros militares o en asentamientos civiles que cuentan con un alto número de población militar, que podrían ser equiparados con Maguncia y Augst en la frontera del $\operatorname{Rin}^{37}$. Estos datos, parecen indicarnos que la composición del ejército de Oriente asentado en estos territorios en época bajoimperial y bizantina inicial, fue muy distinta a la de los efectivos del ejército occidental, por lo menos a tenor de sus hábitos alimenticios.

Creo que hay que aceptar una presencia de contingentes poblacionales "bárbaros" en el ejército y en la sociedad de las provincias fronterizas tanto del oriente como del occidente romano. Sin embargo, aunque es posible que la incidencia porcentual fuera algo mayor en las regiones centro y noreuropeas, ésta nunca debió de ir más allá de una remarcable minoría, quienes evidentemente llamaría la atención a los escritores del momento, que verían en ello un síntoma de los nuevos tiempos y de la crisis del mundo romano, pero que por el contrario no parece haber dejado mucho rastro en el registro arqueológico.

\section{CONCLUSIÓN.}

Tal vez la conclusión más evidente a la que podemos llegar al intentar acercarnos al tema de las importaciones de origen peninsular en el área fronteriza del Rin sea, como ya he repetido a lo largo de este trabajo, la excesiva escasez de datos y la fragmentación de los mismos, que si bien es un problema constante en la investigación de carácter histórico y arqueológico, en este caso

${ }^{37}$ Espero que este estudio sea pronto complementado con uno similar en el que se analicen establecimientos de corte civil, principalmente las capitales de las provincias fronterizas orientales, para que de este modo también puedan aportarse datos comparativos con centros civilies en Occidente. 
resulta bastante significativo al tratarse de un área muy extensa y donde las intervenciones arqueológicas están desde hace mucho tiempo a la orden del día. No obstante, para intentar romper esta situación de precariedad en la que se encuentra la investigación, creo que lo mejor que se puede hacer es empezar a abordar el tema de estudio y así intentar facilitar el que comience a salir del anonimato. De este modo, por muy frágiles, efímeras o minúsculas que puedan ser las conclusiones que se saquen de la situación que actualmente se tiene sobre la presencia de ánforas hispanas en el limes renano, creo que cuanto menos hay que plantearlas.

Basándonos en la muestra analizada en este artículo, en un principio puede decirse que tanto en Maguncia como en Augst hay una reducción significativa del número de importaciones desde mediados del siglo III. Si bien es cierto que igualmente se observa una clara disminución del área de ocupación urbana, ligada a un evidente descenso de la población de ambos núcleos, hay que aceptar que el volumen anfórico parece contraerse aún en mayor medida y que en teoría, el consumo por habitante de los productos envasados en ánforas sería menor que en épocas anteriores. Tal vez también haya que aceptar que a pesar de ser respectivamente dos de los núcleos más importantes del medio y alto Rin, la riqueza de sus habitantes pudo haber disminuido, si bien, desde mi punto de vista, el hecho más decisivo sería que en ambos lugares parece prevalecer el carácter de fortaleza defensiva que adquieren desde fines del siglo III, que está por encima de su función como núcleos civiles y administrativos. Ello conllevaría un mayor peso de los militares dentro del conjunto de sus poblaciones, y por lo tanto -si aceptamos la premisa de que en la Annona militaris del Bajo Imperio en Occidente no cubre la llegada de aceite de oliva y de salazones en el norte de Galia-, una disminución del volumen general de importación de ánforas.

El caso de Colonia se presenta de una manera distinta, pues las cúpulas de Sankt Gereon nos hablan de una importación masiva de ánforas de aceite de oliva béticas, en concordancia prácticamente con los niveles conocidos para época altoimperial en la propia ciudad. Si bien es cierto que tan sólo se trata de un único conjunto cuyo conocimiento se debe bastante al azar y, aunque es posible que en Maguncia, como capi- tal de la provincia Germania II, pudieran haber existido igualmente edificaciones de gran prestigio en relación con la administración y capas altas de la sociedad, no hay que olvidar que la importancia de Colonia parece crecer desde finales del siglo III, mientras que la de Maguncia y Augst disminuye con respecto a los primeros siglos de dominación romana. Este hecho, llevaría a que en la capital de la Germania II, se instalase una élite tanto militar como civil, que demandase en mayor medida productos de importación.

Desde luego, el personaje que estaba enterrado en Sankt Gereon pertenecía a la élite local y era alguien con unas costumbres plenamente romanas. Dejando a un margen la función que pudiera haber tenido dentro de la sociedad de Colonia, lo que sí que creo conveniente resaltar es que el arquitecto que ejecutó la obra probablemente no fuera originario de Germania, o en caso de que lo hubiera sido, debía de haber viajado bastante, por lo menos tanto como para haber estado en Roma, donde ya a principios del siglo IV se está experimentando con la utilización de ánforas para la construcción de bóvedas de gran tamaño o de dificultad técnica, algo que no parece ocurrir en otras partes del Imperio. Hasta el momento no se tiene constancia de algún otro lugar fuera de la capital de Occidente en el que se documente el uso de ánforas en bóvedas en esta época y, aunque hay que ser cautos, creo que Sankt Gereon es una excepción que tiene que ponerse en relación con la presencia en Colonia de gente que conoce y está acostumbrada a las modas y técnicas constructivas de Roma.

Ya ha sido mencionado con anterioridad que el volumen de ánforas utilizadas en la construcción del mausoleo de Sankt Gereon, denota la vitalidad de las exportaciones de aceite del Valle del Guadalquivir hacia el Rin, pero conviene no olvidar que la capacidad de las ánforas olearias sudhispanas tardoantiguas es bastante más reducida que la que presentaban sus predecesoras altoimperiales. Como bien han señalado numerosos estudiosos, la exportación de productos de la cuenca del Guadalquivir se restringe progresivamente desde inicios del siglo III. Si bien este no es el lugar para ahondar en las causas de dicho descenso -ligado indudablemente a intereses impuestos desde Roma- la consecuencia más visible es el fin del Monte Testaccio y el aumento constante de las exportaciones de aceite del 
África Proconsular y Tripolitana por toda la cuenca mediterránea occidental ${ }^{38}$. Así, a pesar de que está constatada la continuidad de la llegada de aceite bético a Roma durante los primeros decenios del siglo IV d.C. ${ }^{39}$, desde la mitad de esta centuria prácticamente no se encuentran ánforas olearias sudhispanas en las regiones mediterráneas extrapeninsulares.

Ahora bien, ¿qué ocurre en las regiones más septentrionales del occidente europeo? A pesar de que se cuenta con pocos datos aparte de los aquí presentados, me atrevería a decir que no parece que la situación pueda extrapolarse al norte de Europa, donde las ánforas africanas se presentan en cantidades muy escasas y siempre menores a las de origen hispano. El ejemplo de Augst tal vez sea el más ilustrativo entre los tres tratados en este trabajo, pero creo que puede extrapolarse al conjunto de estas regiones. Si bien Colonia es un caso único en las regiones del norte del Imperio, no por ello deja de tener gran trascendencia pues nos indica directamente acerca de la relevancia que las regiones hispanas tuvieron en el suministro de productos anfóreos al resto de regiones de la Prefectura de las Galias, en especial a los territorios norteños, como Britannia y el área renana.

$\mathrm{Si}$ atendemos a los parámetros y al volumen en los que parece que se desenvolvió la economía de las regiones Germanas en los últimos tiempos de dominación romana, puede decirse que las ánforas de origen hispano gozaron de una buena aceptación en los mercados norteños. Los vínculos comerciales que se habían forjado y perdurado a lo largo de prácticamente tres siglos, debieron de seguir manteniéndose hasta el final de la dominación romana. Probablemente la propia inercia y la cercanía geográfica jugarían un papel

\footnotetext{
${ }^{38}$ En la parte oriental del Mediterráneo la presencia de ánforas africanas es por el momento muy escasa, lo cual contrasta con las cantidades relativamente altas de Terra Sigillata africana que se encuentran en muchos yacimientos. En Occidente por el contrario, se encuentran ejemplares de procedencia africana en prácticamente cualquier yacimiento, si bien, su presencia comienza a ser abrumadora a partir del siglo V d.C. Hay que destacar que en la propia Península Ibérica, a partir de esta fecha, al igual que ocurre con la sigillata, las ánforas africanas son también mayoría, encontrándose muy pocas producciones hispanas desde el último cuarto del siglo V. Un buen ejemplo son los contextos catalanes de estos momentos, destacando la publicación de J.A Remolà para Tarragona (Remolà, 2000), que en líneas generales parece que puede generalizarse para otros núcleos urbanos como por ejemplo Barcelona.
}

fundamental en la conservación de los mismos, pero hay que pararse a reflexionar y admitir que éstos vínculos habrían acabado diluyéndose de no haber sido por la conveniencia de los poderes políticos, que probablemente lejos de romper unas estructuras de comercio interregionales que seguían mostrándose eficaces para las regiones en ellas involucradas, simplemente se dedicaron a retocarlas. Desde mi punto de vista, el que Hispania y Germania formasen desde época de Constantino parte de una misma realidad políticoadministrativa como fue la Prefectura de las Galias, es un motivo importante para pensar que los productos hispanos seguían manteniendo una posición de privilegio dentro de los mercados ger$\operatorname{manos}^{40}$. Aún así, no pueden dejarse a un lado las transformaciones a las que se asistió en el mundo romano a lo largo del siglo III, ni la nueva evolución que adquieren las distintas regiones del mismo desde época de Diocleciano y Constantino.

En el caso concreto que nos ocupa, estos cambios afectaron principalmente a la propia naturaleza del consumo, es decir al tipo de demanda, que se transformó con respecto al periodo altoimperial al cambiar la naturaleza misma de los consumidores. Durante los primeros siglos de dominación romana, el ejército se había mostrado como el principal consumidor de productos envasados en ánforas, seguido por las élites ciudadanas que, una vez la conquista romana se había asentado, no tardaron mucho en asimilar como propios los patrones de consumo "romanos". Esta situación cambiaría completamente a raíz de las reorganizaciones militares que se llevaron a cabo en época de los tetrarcas y de Constantino, ya que, como se ha mencionado con anterioridad, desde

${ }^{39}$ Lancaster (2005:82), siguiendo a J.T. Peña (1999), indica que la alta presencia de ánforas olearias béticas documentadas en varios edificios de la primera mitad del siglo IV en Roma, bien pueda deberse a la situación política del momento, con las provincias del norte de África bajo control del usurpador Lucio Domicio Alejandro, lo que habría provocado el corte de cualquier tipo de envío ligado a la Annona. Desde mi punto de vista, Peña hace un uso un tanto particular de las fuentes escritas para justificar esta hipótesis. Aún así, creo que en ningún momento ha de quedar descartada.

${ }^{40} \mathrm{Al}$ igual que los productos africanos e Italia, ya que ambas provincias formaron parte de la misma prefectura. Esta premisa ya fue planteada por J. Remesal a inicios de los años ochenta (Remesal, 1983: 115). 
este momento el grueso de las tropas pasó a ser reclutado in situ, entre las capas rurales más desfavorecidas de la sociedad germanorromana ${ }^{41} \mathrm{o}$ en su defecto de los territorios galos más cercanos, por lo que hay que tener en cuenta, que estas gentes, tanto a lo largo del periodo altoimperial como ahora en el Bajo Imperio, siempre permanecieron al margen del comercio interregional y salvo en contadas ocasiones, no debieron de consumir ninguno de los productos que llegaban en las ánfo$\mathrm{ras}^{42}$. Por este motivo, puede intuirse que el principal consumidor de "productos anfóricos" de época altoimperial, es decir el ejército, prácticamente dejaría de tener relevancia en el periodo aquí tratado.

El consumo civil de "bienes anfóricos" en las provincias germanas, debió de estar restringido en su mayor parte a las élites provinciales que, al igual que los altos cargos del ejército, habrían consumido productos de alta calidad, importados desde todos los rincones del Imperio. Con la importancia que adquiere Colonia y sobre todo con el traslado de la corte del César de Occidente a Trier, el número potencial de consumidores de alto rango debió de aumentar considerablemente. El carácter de este consumo es en principio distinto al de las tropas, ya que sus consumidores son gente con bastante poder adquisitivo, que demandarían productos de calidad y de muy variada procedencia. Aunque puede que en cierto modo el comercio de estos bienes pudiera haber estado relacionado con la Annona imperial, sobre todo en lo que a la corte de Trier se refiere, es más que probable que una gran parte del mismo se realizaría por medio de mercaderes privados.

La posible preeminencia de un comercio de bienes anfóricos de alta calidad, o por lo menos de alto precio en el área central de Germania, podría llevar a plantearnos cuestiones tan interesantes como la posible adaptación de los productos his-

\footnotetext{
${ }^{41}$ Hay que tener en cuenta que si descontamos a la población militar asentada, estos campesinos humildes debieron significar una proporción muy elevada de la masa social. Por otra parte, creo conveniente resaltar aquí aunque sea levemente, otra laguna de la investigación relacionada con las ánforas en las tierras del Rin, cual es la práctica ausencia de estudios en los que se haya tratado la presencia de ánforas en las grandes Villae documentadas en estas regiones, ya que únicamente la doctora Ehmig parece haber intentado un acercamiento al tema (Ehmig, 2007).
}

panos a un nuevo mercado más exigente, en el que prima la calidad sobre la cantidad, bastante distinto al de épocas anteriores. No obstante, tengo que reconocer que es muy temprano para avanzar en este tema, más aún teniendo en cuenta del escaso material arqueológico con el que se cuenta.

A modo de incentivo de cara al futuro, sólo queda plantear que la clave para seguir avanzando en el entendimiento de los procesos comerciales que unieron a las provincias hispanas con las renanas durante los últimos siglos de la dominación romana, pasa por revisar el material de los principales núcleos poblacionales de estos territorios, destacando lo oportuno de llevar a cabo, por dificultoso y largo que pueda ser, un mínimo estudio del material tardoantiguo de lugares como Colonia y sobre todo de Trier, capital imperial y de la Prefectura de las Galias, cuyo vínculo con el área germana está fuera de cualquier duda.

\section{BIBLIOGRAFÍA}

BERNAL CASASOLA, D. (1997). "Las producciones anfóricas del bajo imperio y de la Antigüedad tardía en Málaga: estado actual de la investigación e hipótesis de trabajo", en VVAA. Figlinae Malacitanae. La producción de cerámica romana en los territorios malacitanos. Málaga, 239-259.

BERNAL CASASOLA, D. (1998). Los Matagallares (Salobreña, Granada) un centro romano de producción alfarera en el siglo III d.C. Granada.

BERNAL CASASOLA, D. (2000). "La producción de ánforas en la Bética en el s.III y durante el Bajo Imperio romano". Ex Baetica Amphorae: conser$v a$, aceite y vino de la Bética en el Imperio Romano. Volumen 1. Ecija, 239-372.

BERNI MILLET, P. (1998). Las ánforas de aceite de la Bética y su presencia en la Cataluña romana. Barcelona.
${ }^{42}$ Con ello no se pretende decir que no pudieran haber tenido ocasionalmente contacto con dichas ánforas, bien debido a la compra del producto que transportaban por parte de la comunidad en una ocasión especial, por ejemplo la compra de un vino de alta calidad para el consumo en un día festivo, o bien por la compra del envase una vez que éste fue desprovisto de su contenido, como probablemente fuera el caso en Wahlheim o en De Horden (ver nota 32). Aún así, para que estos casos fueran posibles, tendría que ser condición sine quod la cercanía a las vías de distribución por la que las mercancías llegaban a los puntos principales de consumo. 
BONIFAY, M. (2004). Etudes sur la céramique romaine tardive d'Afrique. BAR 1301. Oxford.

BRULET, R. (1993). "Les dispositifs militaires du Bas-Empire en Gaule septentrionale". L'armée romaine et les barbares. Du III au VII siècle. Textes réunis par Francoise Vallet et Michel Kazanski. Rouen, 36-44.

BRUN, J-P. (2004). Archéologie du vin et de l'huile dans le monde romanine. París.

BRUN, J-P. (2005). Archéologie du vin et de l'huile en Gaule. París.

CARRERAS MONFORT, C. (1998). Britannia y el Mediterráneo: Estudios sobre el abastecimiento de aceite bético y africano en Britannia. Barcelona.

CARRERAS MONFORT, C. y Williams, D. (2003). "Spanish olive oil trade in late roman Britain: Dressel 23 Amphorae from Winchester". Journal of roman Pottery Studies, n 10. Oxford, 64-68.

CARRIÉ, J-M. (2004). "Le système de recrutement des armées romaines de Dioclétian aux Valentiniens". Yann Le Bohec y Catherine Wolff ed. L'armée romaine de Dioclétien à Valentinien I. Lyon, 371-387.

CESA, M. (1993). “ Römisches Heer und barbarische Föderaten: Bemerkungen über die weströmische Politik in den Jahren 402-412". L'armée romaine et les barbares. Du III au VII siècle. Textes réunis par Francoise Vallet et Michel Kazanski. Rouen, 105-111.

ECK, W. (2004). Köln in römischer Zeit : Geschichte einer Stadt im Rahmen des Imperium Romanum. Geschichte der Stad Köln, Band 1. Colonia.

-EHMIG, U. (2003). Die römischen Amphoren aus Mainz. Frankfurt am Main.

EHMIG, U. (2007). Die römischen Amphoren im Umland von Mainz. Frankfurt am Main.

ELTON, H. (1996). Warfare in Roman Europe, AD 350-425. Oxford.

FERNÁNDEZ GARCÍA, M. I. (2004). "Alfares y producciones cerámicas en la povincia de Granada. Balance y perspectivas". Figlinae Beaticae: Talleres alfareros y producciones cerámicas en la Bética romana (ss.II a.C.-VII d.C.): actas del Congreso Internacional, Cádiz, 12-14 de noviembre 2003. BAR 1266. Oxford, 239-272.

FRITZ, M. (2001). Annona Militaris. Die Heeresversorgung im Spätantike Ägyptien. Ein Beitrag zur Verwaltung und Heeresgeschichte des Römisches Reiches im 3 bis $6 \mathrm{Jh}$. Florencia.
GARCÍA MORENO, L. (1981). “¿Continuidad o discontinuidad de la producción oleícola hispana durante la Antigüedad tardía (SS V-VII)?". Producción y comercio de aceite en la Antigüedad. Primer Congreso Internacional. Madrid, 301-309.

GOTTSCHALK, R. (1999). “Zur ethnischen Einordnung einiger spätantike Gräber des Rheinlandes". Thomas Fischer, Gundolf Precht und Jaroslav Tejral ed. Germanen Beiderseits des Spätantiken Limes. Colonia-Brno, 81-92.

HERZ, P. (1988). Studien zur römischen Wirtschaftsgesetzgebung: Die Lebensmittelversorgung. Stuttgart.

KARAGIORGOU, O. (2001). "LR2: a Container for the Military annona on the Danubian Border?" Sean Kingsley \& Michael Decker ed. Economy and Exchange in the East Mediterranean during Late Antiquity. Oxford, 129-166.

KAZANSKY, M. (1993). "Les Barbares orientaux et la défense de la Gaule au IV et V siècles". L'armée romaine et les barbares. Du III au VII siècle. Textes réunis par Francoise Vallet et Michel Kazanski. Rouen, 27-41.

KEAY, S. J. (1986). Late roman Amphorae in the western Mediterranean. A tipology and economic study: The Catalan evidence. BAR 196. Oxford.

LAGÓSTENA BARRIOS, L. (2001). La producción de salsas y conservas de pescado en la Hispania romana. Barcelona.

LANCASTER, L.C. (2005). Concrete Vaulted Constructions in Imperial Rome. Innovations in Context. Cambridge.

LE BOHEC, Y. (2006). L'Armée romaine sous le BasEmpire. París.

LEE, D. (2007). War in Late Antiquity. Oxford.

LIBESCHUETZ, W. (2007). "Warlords and Landlords". Paul Erdkamp ed. A companion to the Roman Army. Oxford.

LO CASCIO, E. (2003). "Mercato Libero e "Commercio amministrato" in età tardoantica". Mercanti e Politica nel Mondo Antico. Roma, 307-325.

MARLIÈRE, E. (2002). L'outre et le tonneau dans l'Occident romain. Montagnac.

MARTIN-KILCHER, S. (1987). Die römischen Amphoren aus Augst und Kaiseraugst. Volumen I. Augst.

MARTIN-KILCHER, S. (1994a). "Verbreitungskarten römischer Amphoren und Absatzsgebiete importierter Lebensmittel. 
Münstersche Beiträge zu handel Geschichte, $\mathrm{n}^{\circ}$ 13, Volumen 2. Münster, 95-122.

MARTIN-KILCHER, S. (1994b). Die römischen Amphoren aus Augst und Kaiseraugst. Volúmenes II, y III. Augst.

NICASIE, M. J. (1998). Twilight of Empire. The Roman Army from the reign of Diocletian until the battle of Adrianopolis. Amsterdam.

OLDENSTEIN, J. (1993). "La fortification d'Alzey et la défense de la frontière romaine au IV et V siècles", en VV.AA. L'armée romaine et les barbares. Du III au VII siècle. Textes réunis par Francoise Vallet et Michel Kazanski. Rouen, 177188.

PEACOCK, D. P. S. y Williams, D. (1988). Amphorae and the roman economy. An introductory guide. Londres.

PEÑA, J. T. (1999). The urban economy during the early dominate: pottery evidence from the Palatine Hill. BAR, 784. Oxford.

PIRLING, R. (1993). "Römische Gräber mit barbarischem Einschlag auf den Gräberfeldern von Krefeld-Gellep“. L'armée romaine et les barbares. Du III au VII siècle. Textes réunis par Francoise Vallet et Michel Kazanski. Rouen, 109124.

RASCH, J. J. (1984). Das Maxentius-Mausoleum an der Via Appia in Rom. Mainz.

RASCH, J. J. (1993). Das Mausoleum bei Tor de'Schiavo in Rom. Mainz.

REICHMANN, C. (1999). “ Germanen im spätantiken Gelduba (Krefeld-Gellep)". Thomas Fischer, Gundolf Precht und Jaroslav Tejral ed. Germanen Beiderseits des Spätantiken Limes. Colonia-Brno, 129-144.

REMOLÀ VALLVERDÚ, J. A. (2000). Las ánforas Tardo-Antiguas en Tarraco (Hispania Tarraconensis). Barcelona.

REMESAL RODRÍGUEZ, J. (1983). "Transformaciones en la exportación del aceite bético a mediados del siglo III d.C". Producción y comercio de aceite en la Antigüedad. Segundo congreso internacional. Madrid, 115-131.

REMESAL RODRÍGUEZ, J. (2002). "Baetica and Germania. Notes on the concept of provoncial interdependence". The roman army and the economy. 293-308. Amsterdam.

RODRÍGUEZ ALMEIDA, E. (1980). "Vicissitudini nella gestione del commercio dell'olio betico da Vespasiano a Severo Alessandro". Memoirs of the American Academy in Rome, 36. Roma, 277-290.
SCHWAB, O. (2002). "St. Gereon zu Köln. Untersuchungen zum Spätantiken Gründungsbau“. Kölner Jahrbuch 35. Colonia, 7206.

SEILLIER, C. (1993). "Les Germains dans l'armée romaine tardive en Gaule septentionale. Le témoignage de l'archéologie". L'armée romaine et les barbares. Du III au VII siècle. Textes réunis üas Francoise Vallet et Michel Kazanski. Rouen, 45-60.

SERRANO RAMOS, E. (2004). "Alfares y producciones cerámicas en la provincia de Málaga. Balance y perspectivas. Figlinae Beaticae: Talleres alfareros y producciones cerámicas en la Bética romana (ss.II a.C.-VII d.C.): actas del Congreso Internacional, Cádiz, 12-14 de noviembre 2003. BAR 1266. Oxford, 161-194.

SOUTHERN, P. (2006). The Roman Army. A social and Institutional History. Oxford.

STICLER, T. (2007). "The Foederati". Paul Erdkamp ed. A companion to the Roman Army. Oxford, 495-514.

VERSTEGEN, U. (2006). "Ausgrabungen und Bauforschungen in Sankt Gereon zu Köln". Kölner Forschungen 91. Mainz am Rhein.

VV.AA. (1987). Die Römer in Nordrhein-Westfalen. Stuttgart.

VV.AA. (1990). Die Römer in Rheinland-Pfalz. Stuttgart.

WHITTAKER, C. R. (1983). "Trade and Frontiers of the Roman Empire". Peter Garnsey \& C.R. Whittaker ed. Trade and Famine in classical Antiquity. Cambridge, 110-127.

WOLFRAM, H. (1993): "L'armée romaine comme modèle pour l'exercitus barbarorum". L'armée romaine et les barbares. Du III au VII siècle. Textes réunis par Francoise Vallet et Michel Kazanski. Rouen, 54-66.

ZUKERMAN, C. (1993): "Les Barbares romains: au sujet de l'origine des auxilia tétrarquiques". L'armée romaine et les barbares. Du III au VII siècle. Textes réunis par Francoise Vallet et Michel Kazanski. Rouen, 125-140. 


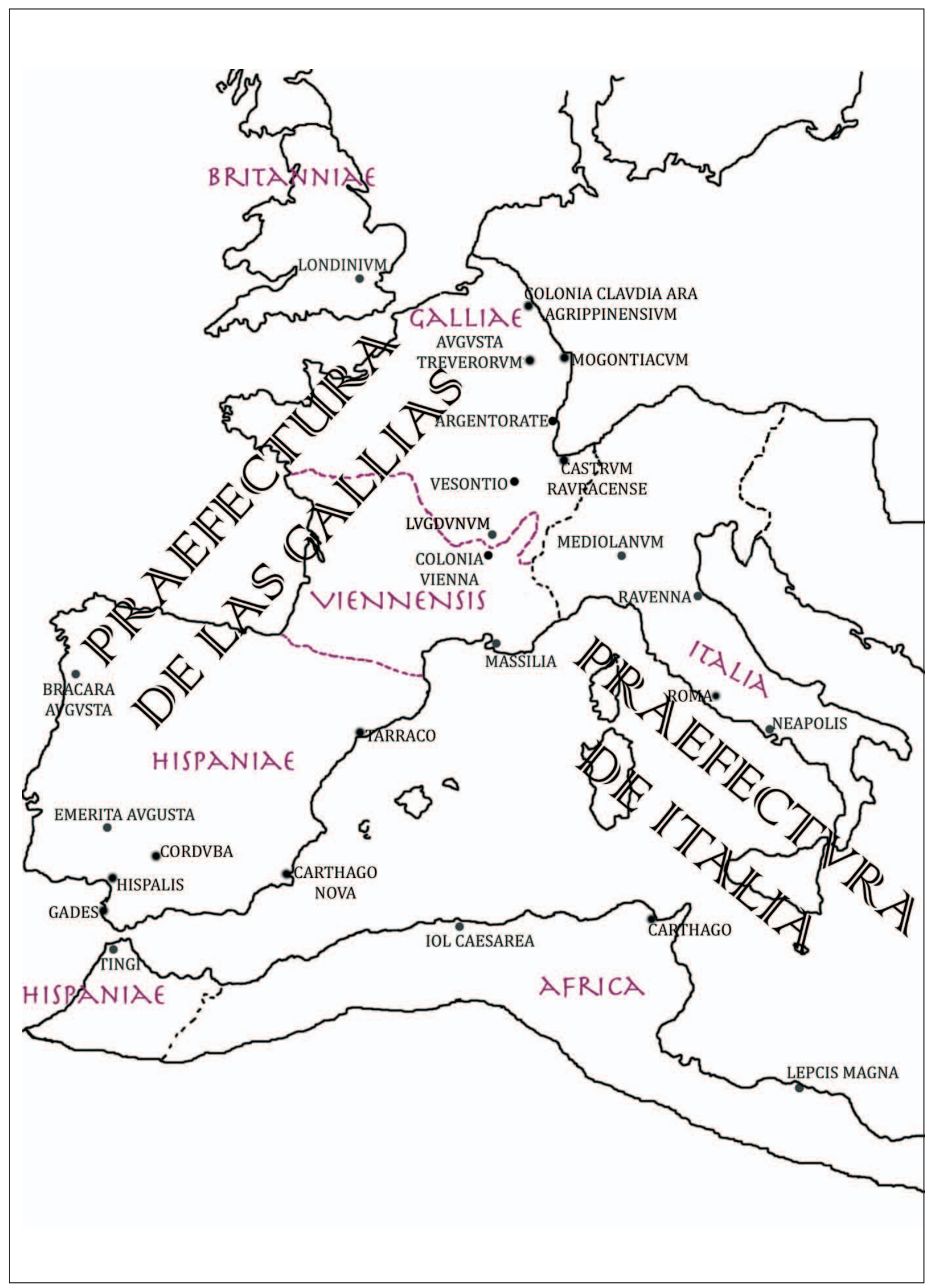

Figura 1: El imperio romano de occidente a partir de la reordenación territorial de época de Diocleciano. 
Table 1: Comparison of weights and volumes of some common amphora types

\begin{tabular}{lccc}
\hline \multicolumn{1}{c}{ Type and publication } & Volume & Weight & Litres/Kg \\
\hline Dressel 1B (Class 4) & & & \\
Hawkes and Hull, 1947, no. 181 & 22.00 & $b 25.00$ & 0.88 \\
\hline Dressel 2-4 (Class 10) & & & \\
Ibid., 182B & 224.50 & $b 12.00$ & 2.04 \\
Ibid., 183B & 18.00 & $b 16.50$ & 1.09 \\
Ibid., 183C & 233.00 & $b 16.50$ & 2.00 \\
Average & 25.20 & 15.00 & 1.68 \\
\hline Haltern 70 (Class 15) & & & \\
lbid., 185A & 25.50 & $b 15.50$ & 1.65 \\
Colls et al., 1977: 33 & 34.75 & 20.50 & 1.70 \\
Average & 30.13 & 18.00 & 1.67 \\
\hline Dressel 20 (Class 25) & & & \\
Dressel, 1879, no. 106 & 39.00 & 19.90 & 1.96 \\
Ibid., no. 110 & 58.50 & 24.50 & 2.39 \\
Ibid., no. 104 & 59.00 & 27.80 & 2.12 \\
Ibid., no. 99 & 63.00 & 27.00 & 2.33 \\
Zevi \& Tchernia, 1969: 177 & 72.25 & 37.20 & 1.94 \\
Ibid. & 80.50 & 35.80 & 2.24 \\
Ibid. & 77.50 & 32.32 & 2.40 \\
Colls et al., 1977: 85-larger & 69.80 & 28.40 & 2.46 \\
Ibid., smaller type & 45.95 & 22.85 & 2.01 \\
Average & 62.83 & 28.42 & 2.21 \\
\hline Africana Grande (Class 34) & & & \\
Zevi \& Tchernia, 1969: 177, & 68.00 & 19.50 & 3.49 \\
no. 15301 & & & \\
Ibid., no. 15303 & 56.50 & 17.30 & 3.27 \\
Ibid., no. 15302 & 61.80 & 17.20 & 3.59 \\
Ibid., no. 15512 & 62.70 & 17.30 & 3.73 \\
Average & & & 3.52 \\
\hline
\end{tabular}

Tripolitanian (Class 36 and 37)

(from Pompeii)

Panella, 1977: 14194

Ibid., no. 420

Ibid., no. 445

Ibid., no. 1393

lbid., no. 423

lbid., no. 412

Ibid., no. 422

Ibid., no. 414A

Ibid., no. 414

Ibid., no. 210

Ibid., no. 449

Ibid., no. 433

Ibid., no. 430

57.00

$\mathbf{5 4 . 5 0}$

60.50

56.50

55.50

57.00

58.00

50.00

50.10

54.50

53.00

58.00

59.00

56.18

14.00
14.00
15.50
17.50
17.0
17.00
17.00
14.00
14.90
15.50
17.00
17.00
15.00
15.86

4.07

3.89

3.90

3.23

3.26

3.53

3.41

3.60

3.36

3.52

3.12

3.41

3.93

3.56

Notes: $a$. Capacities taken from Sealey (1985). b. Weights recorded by Ms . J. Bukenberger in 1975. 


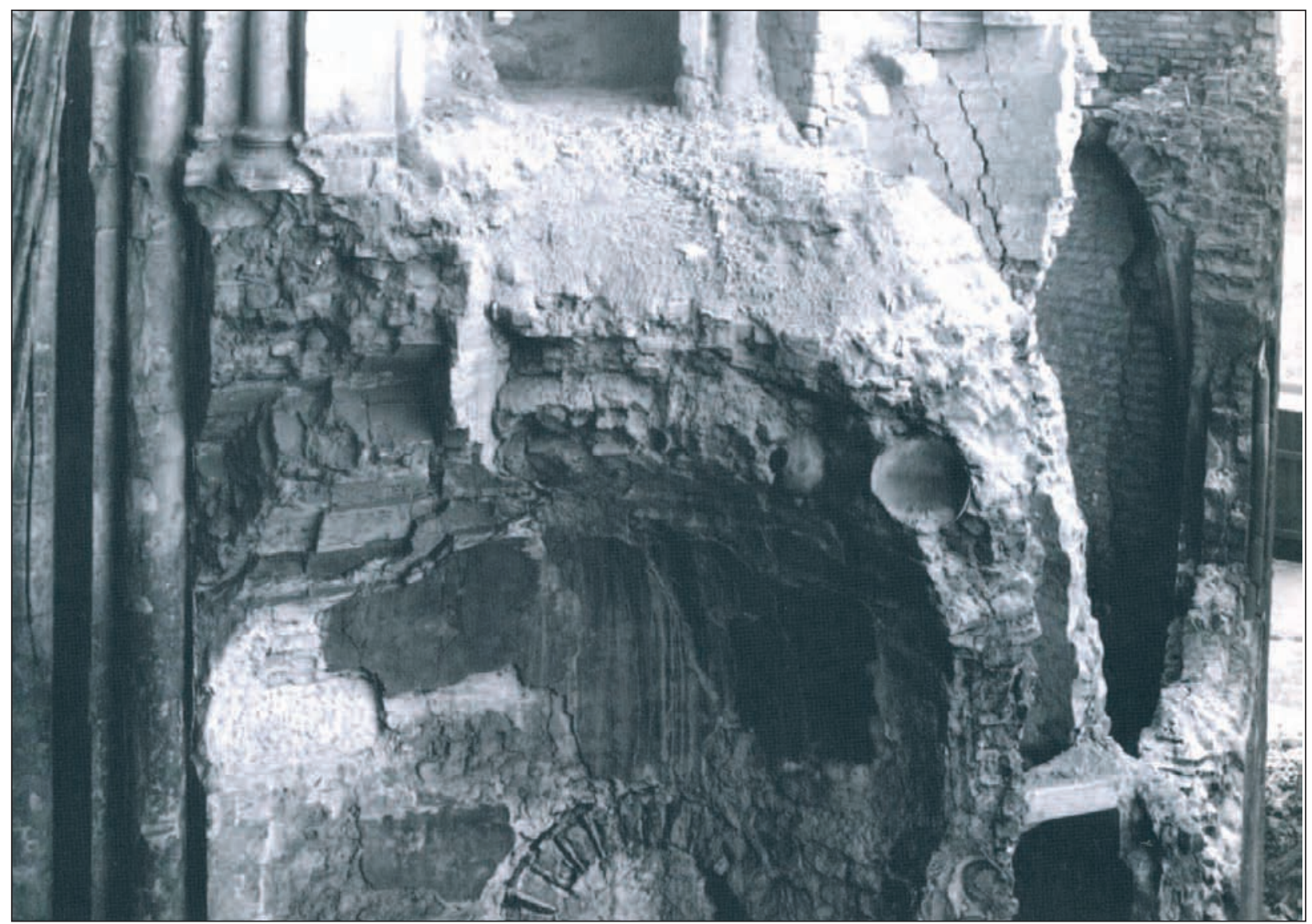

Figura 3: Interior de una de las cúpulas de Sankt Gereon tras los bombardeos aliados sobre Colonia. Pueden observarse perfectamente varias ánforas. Foto: Ute Verstegen (2006).

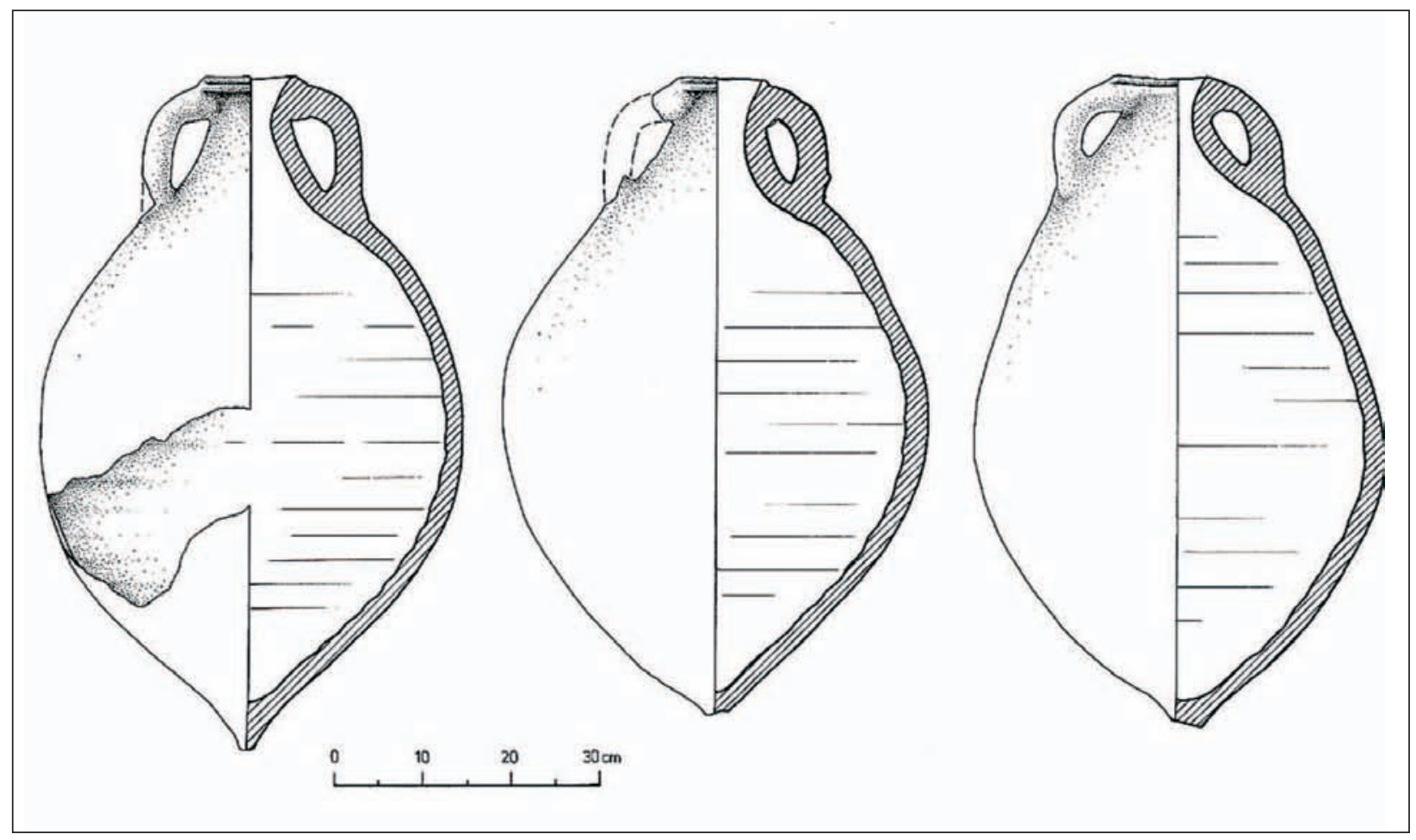

Figura 4: Dressels 23 de Sankt Gereon, según dibujo de Ute Verstegen (2006). 


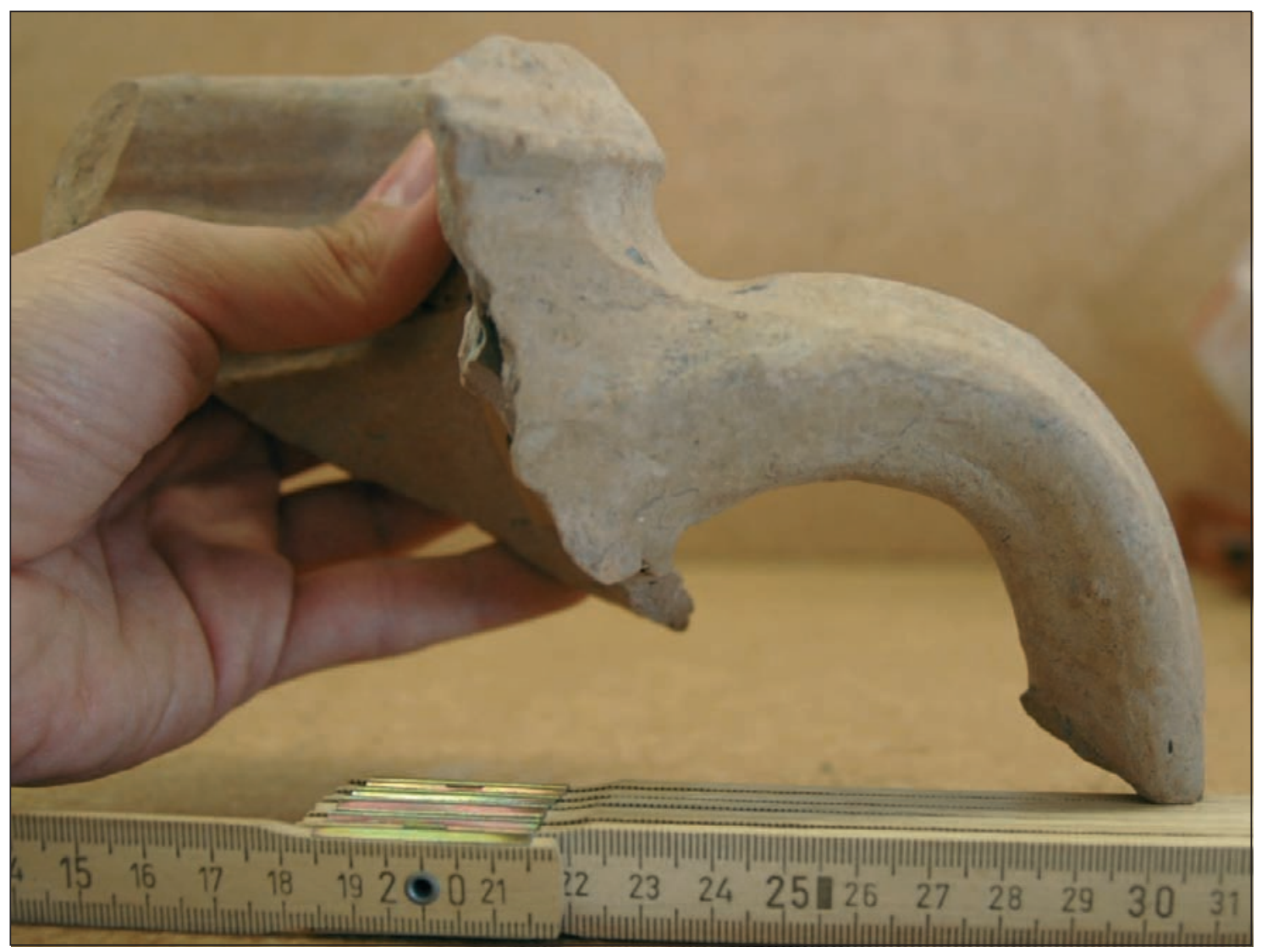

Figura 5: Parte superior de Dressel 23 aparecida en un contexto del siglo IV en Augst. Foto del autor.

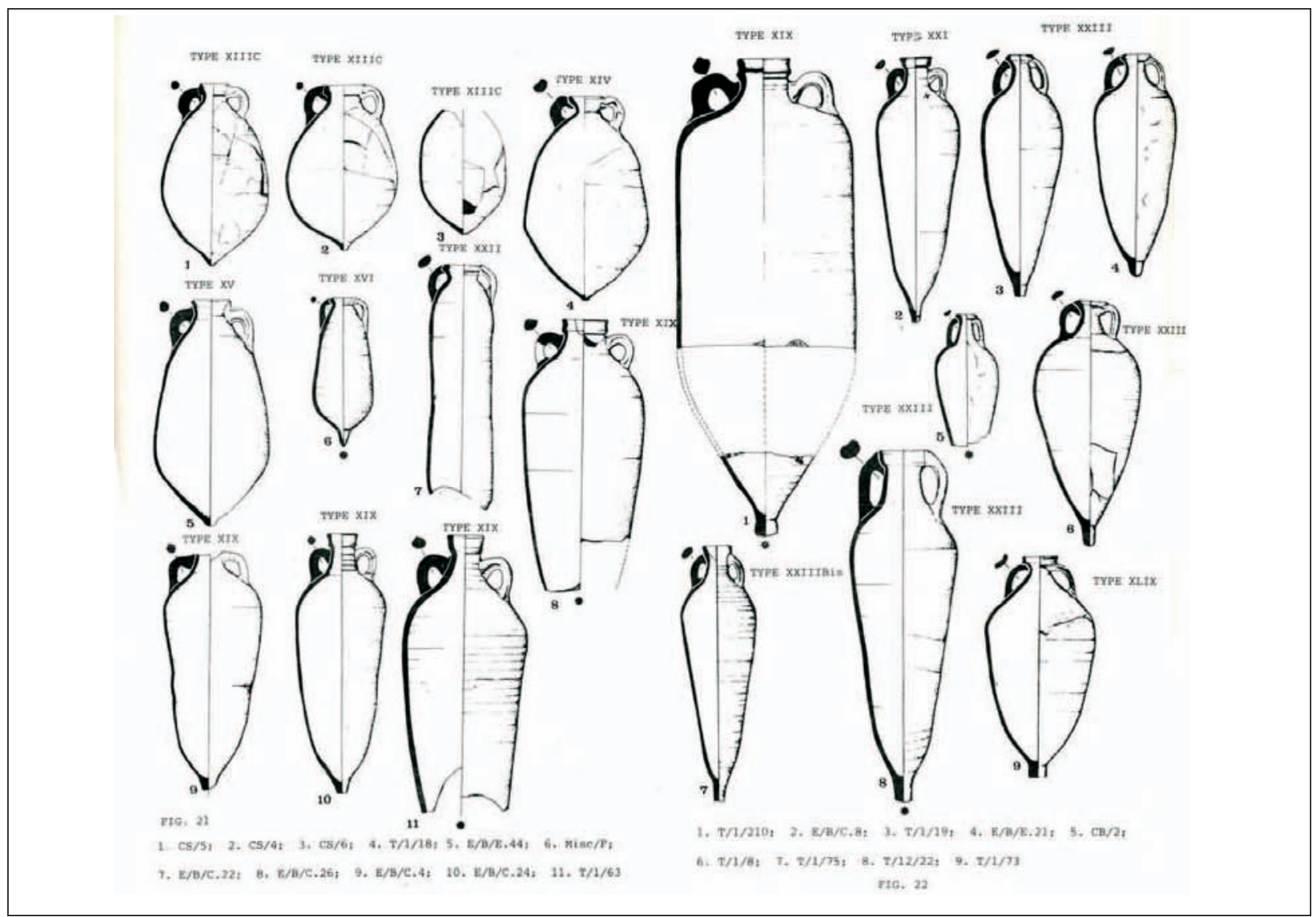

Figura 6: Principales tipos de ánforas hispanas tardoantiguas, según Simon. J. Keay (1984). 


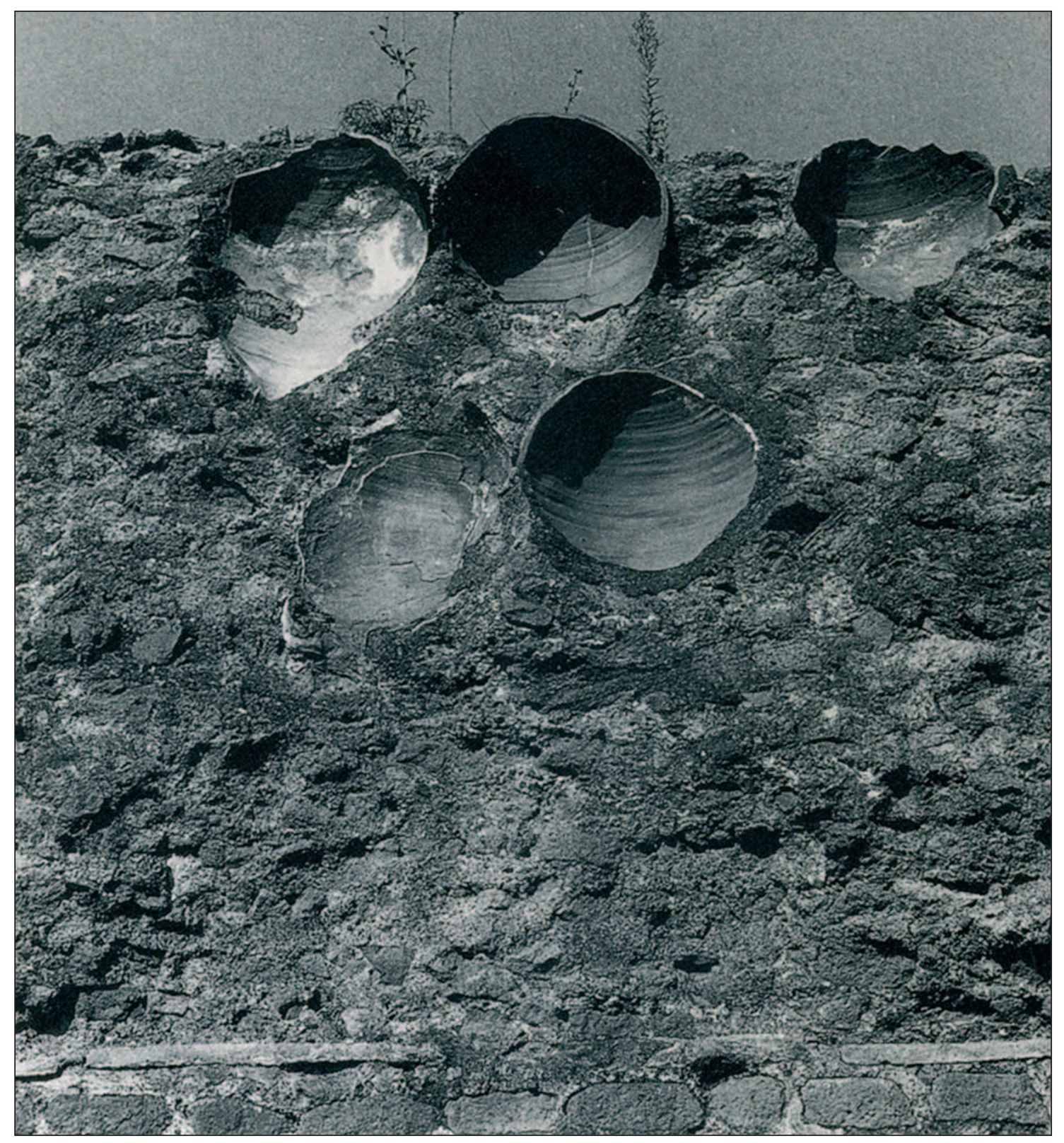

Figura 7: Vista de ánforas Dressel 23 utilizadas en la construcción de las bóvedas del denominado circo de Majencio en Roma. Foto: Jürgen Rasch (1993). 
